Florida International University FIU Digital Commons

3-27-1996

\title{
Perceptions of nurses and clients related to empathic interactions
}

Patricia Christine Calhoun

Florida International University

DOI: $10.25148 /$ etd.FI14052539

Follow this and additional works at: https://digitalcommons.fiu.edu/etd

Part of the Nursing Commons

\section{Recommended Citation}

Calhoun, Patricia Christine, "Perceptions of nurses and clients related to empathic interactions" (1996). FIU Electronic Theses and Dissertations. 1975.

https://digitalcommons.fiu.edu/etd/1975

This work is brought to you for free and open access by the University Graduate School at FIU Digital Commons. It has been accepted for inclusion in FIU Electronic Theses and Dissertations by an authorized administrator of FIU Digital Commons. For more information, please contact dcc@fiu.edu. 
FLORIDA INTERNATIONAL UNIVERSITY

Miami, Florida

\section{PERCEPTIONS OF NURSES AND CLIENTS RELATED TO EMPATHIC INTERACTIONS}

A thesis submitted in partial satisfaction of the

requirements for the degree of

MASTER OF SCIENCE

IN

NURSING

by

Patricia Christine Calhoun

1996 


\section{To: Linda Simunek}

School of Nursing

This thesis, written by Patricia Christine Calhoun and entitled, Perceptions of Nurses and Clients Related to Empathic Interactions, having been approved in respect to style and intellectual content, is referred to you for judgement.

We have read this thesis and recommend that it be approved.

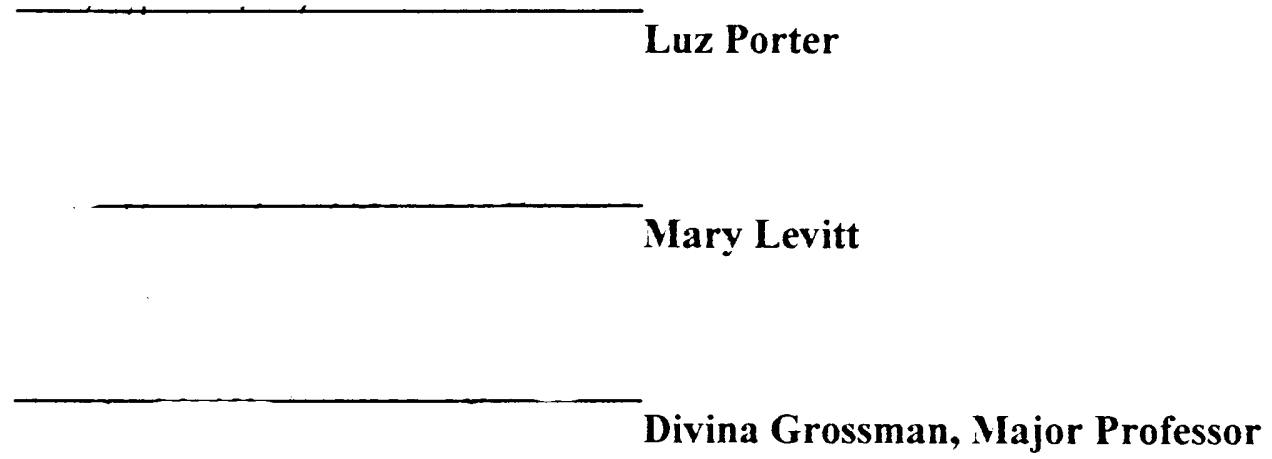

Date of Defense: March 27, 1996

The thesis of Patricia Calhoun is approved.

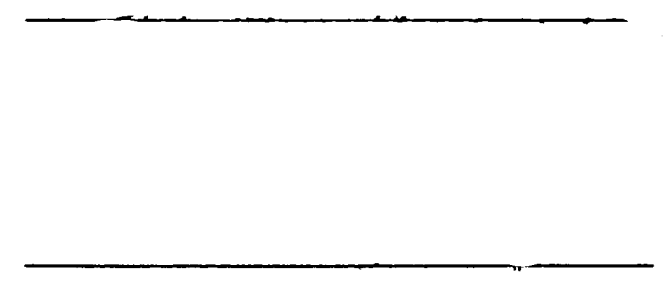

Dean Linda Simunek

School of Nursing

Richard Campbell

Dean of Graduate Studies

Florida International University, 1996 


\title{
ABSTRACT OF THE THESIS \\ PERCEPTIONS OF NURSES AND CLIENTS \\ RELATED TO EMPATHIC INTERACTIONS
}

by

\author{
Patricia Christine Calhoun \\ Florida International University, 1996 \\ Miami, Florida \\ Divina Grossman PhD, Major Professor
}

The definition of empathy is generally agreed upon, although its precise nature and characteristics within a nurse-client relationship are unclear. The perceptions of nurses and clients related to empathic interactions were examined using hospitalized clients and their direct care nurses. A phenomenological approach was chosen for research design and analysis.

Data for the study were collected by interviewing the nurses and clients individually. The interviews were recorded and transcribed. The data were analyzed using the seven step Colaizzi method.

The findings of the study indicate that nurses and clients have a multi-dimensional view of empathy. There is agreement that there is a sense of a connection, presence, energy, and shared nonverbal communication. The process of empathy is accompanied by a sense of self-transposal and resonation with the experience of the other. The 
experience of empathy is felt to be an essential component of nursing that can lead to enhanced well-being. 


\section{TABLE OF CONTENTS}

CHAPTER

PAGE

I. INTRODUCTION

Conceptual Framework

Significance of the Study

Statement of the Problem

Research Purpose

Operational Definitions

Assumptions

Delimitations

Limitations

II. REVIEW OF THE LITERATURE 6

Historical Overview 6

Empathy in Psychology Literature $\quad 7$

Definition of Empathy

Empathy in Nursing Literature

Empathy Measurement

Learning/Teaching Empathy

III. METHODOLOGY

Design and Sample

Setting 
Measurement Tools

Protection of Human Rights $\quad 22$

$\begin{array}{ll}\text { Data Collection } & 23\end{array}$

$\begin{array}{ll}\text { Data Analysis } & 24\end{array}$

$\begin{array}{ll}\text { IV. RESULTS } & 29\end{array}$

Demographic Data 29

$\begin{array}{ll}\text { Protocol Reading } & 29\end{array}$

$\begin{array}{ll}\text { Significant Statements } & 30\end{array}$

$\begin{array}{ll}\text { Formulated Meanings } & 31\end{array}$

$\begin{array}{ll}\text { Theme Clusters } & 40\end{array}$

Exhaustive Description $\quad 40$

$\begin{array}{ll}\text { Fundamental Structure } & 40\end{array}$

$\begin{array}{lll}\text { V. DISCUSSION } & 44\end{array}$

Conceptual Framework $\quad 44$

Implications for Nursing $\quad 46$

Limitations of the Study 49

Credibility of the Results

Recommendations for Further Study $\quad 51$

LIST OF REFERENCES

APPENDIXES

A. Semistructured Interview Questions (Nurse) 62 
B. Invitation to Participate (Nurse) 64

Invitation to Participate (Client) 66

C. Informed Consent Form 68

D. Demographic Information 71

$\begin{array}{ll}\text { E. Transcribed Interviews } & 72\end{array}$

TABLES

1. Significant Statements -Nurse 99

2. Significant Statements -Client 101

3. Theme Clusters from Formulated Meanings Nurses 103

4. Theme Clusters from Formulated Meanings Clients 106

5. Exhaustive Description of Empathy-Nurse Perception 108

6. Exhaustive Description of Empathy-Client Perception 109

7. Fundamental Structure of Empathy-Nurse Perception 110

8. Fundamental Structure of Empathy-Client Perception 111 
The best

and most beautiful

things in the world

cannot

be seen

or even touched

They must be felt with the heart

Helen Keller 


\section{CHAPTER ONE}

\section{INTRODUCTION}

It is generally accepted that the quality of empathy is of fundamental importance in nursing. Empathy is understood to be the ability to enter another person's feelings and see the world through that person's eyes without losing objectivity. Chapman (1983) describes nursing as an interpersonal activity demanding a high level of empathetic awareness. This view has been shared by authors for the past 40 years addressing the concept of empathy.

In 1958, the American Journal of Nursing published a sociological analysis of the nurse's role that described the specialized function of the nursing profession as an expressive role involving the willingness to listen and understand. The writings of Florence Nightingale (1946) and many contemporary theorists present the nurse as one who creates a caring and helping atmosphere in which healing can be facilitated.

Studies have been conducted to assess the level of empathic ability in nursing subjects. The conclusion that nurses are low in empathic ability has been supported by research (Duff \& Hollingshead, 1968; Kalish, 1971; and LaMonica, Carew, \& Winde, 1976). In contrast Forsyth (1980), and Kirk and Johnson (1978) reported high empathic levels among nurses, subjects that were considered high or comparable to those of counselor therapists. Consistently in these studies, used to measure empathy, the validity and reliability of the tool has been questioned. There continues to be considerable 
controversy in the nursing literature surrounding the concept of empathy. At the core of this controversy is considerable confusion about the concept itself.

Nursing research has been fraught with difficulties to define and measure empathy. Reasons for the problems have been suggested (Gould, 1990) to be due to the early uncritical adoption of the concept of empathy based on views of counseling psychology. It has also been proposed that the scales for testing empathy had originally been developed for testing clients in counseling (Morse, et al 1992). It is well understood that more differences than similarities exist between clients in psychotherapy and clients who are physically ill.

In light of these issues it is important that the concept of empathy be examined within the context of nursing practice. The American Nurses' Association (1985) mandated the careful specification of nursing concepts and the development of reliable and valid instruments to measure those concepts. Tilden, Nelson, and May (1990) stated that nursing science has suffered from lack of measures developed according to psychometric principles to insure reliability and validity. They suggest that more attention be paid to concept specification prior to development of the measures. This examination may assist in the future development of valid measuring devices. In this study, characteristics of empathy were explored and described based on perceptions of both nurses and clients.

\section{Conceptual Framework}


The conceptual framework utilized for this study is that of Martha Rogers (1990). Rogers conceptualized a human being as a unitary, four dimensional energy field phenomenon. As unitary beings Rogers (1990) characterized humans as "holistic". Nursing in a holistic manner provides that the whole individual is treated, not just the disease process or pathology. Unitary beings are irreducible wholes that cannot be understood by just examining components or subsystems.

An energy field in Rogers' system is the basic unit of all that exists in the world. Each individual is seen as a distinct energy field possessing an identifying pattern. This field is dynamic and constantly in motion. The fields are infinite and beyond the physical body. Open nature of fields allow for constant flow between fields.

Empathy may be viewed within the context of Rogers' conceptual model. The four-dimensional quality of the human adds to the concept of a three dimensional world. The fourth dimension is a realm without linear space and time. The dimension allows that energy fields exist beyond the space constraints of the physical body and beyond time constraints of the present (Compton, 1989). Empathy encompasses a holistic approach and the "crossing over" phenomenon of empathy can be explained as a blend of energy fields.

\section{Significance of the Study}

The technology of this past decade has changed the nursing practice environment dramatically. In the hospital world of machines, rapidly changing technology, and 
fragmented services, there is an immense need for the human response. The client's need for empathy in this technological environment remains constant (Gagan, 1983).

This study generated data describing the nature and characteristics of the empathic experience within a nurse-patient relationship. Additionally, this study may help in the development of valid and reliable tools for measuring empathy among nurses. Educational programs may also be planned to assist nurses in becoming more empathetic toward their clients.

\section{Statement of the Problem}

Although the definition of empathy is generally agreed upon, its precise nature and characteristics within a nurse-client relationship are unclear. There are components of the nursing empathic process that are not clearly understood. It is not known what nurses and clients perceive as expressions of empathy.

\section{$\underline{\text { Research Purpose }}$}

The purpose of this study is to describe patients' and nurses' perceptions of the empathic process.

\section{Operational Definitions}

The operational definitions of this study are as follows:

1. Nurses - Registered nurses licensed by the Department of Professional Regulation, Board of Nursing.

2. Empathy - The ability to perceive the meanings and feelings of another person and to communicate that understanding to the other (Gagan, 1983). 
3. Client - An individual receiving health care.

4. Perceptions - quick, acute, intuitive cognition (Webster, 1977).

5. Empathic processes - mutual influence of empathy.

\section{Assumptions}

The assumptions of the study are as follows:

1. Client and nurse participants will answer questions honestly and completely.

2. The recorder will accurately record data.

3. The characteristics of the empathic interaction can be identified and articulated.

4. Both clients and nurses can relate past experiences of empathic relationships. 


\section{CHAPTER 2}

\section{LITERATURE REVIEW}

The psychology and counseling literature is replete with research on empathy. Although descriptions of empathy are found in the literature, there is no consistent definition of the concept. Most studies of empathy have been undertaken in the United States and rely on the work of psychotherapists, specifically Carl Rogers.

\section{Historical Overview}

The word empathy is derived from the Greek, "empatheia", which implies an active appreciation of another person's feeling experience (Goldstein \& Michaels, 1985). Modern usage of the word empathy was developed from the German word "einfuhlung", which literally means "feeling oneself into" (Zderad, 1969).

Theodor Lipps (1903), a German philosopher, used the term "empathy" in an esthetics text to refer to the joyful, personal feeling when viewing an object of art. This feeling of aesthetic empathy is commonly experienced as the teary-eyed reaction the viewer may have to a painting or sculpture, or an especially moving passage of music. Lipps asserted that this feeling came from the infusion of oneself into the object being viewed and in feeling a oneness with the object. Empathy may be viewed as an aesthetic form of knowing (Brown, 1990).

The German philosopher Stein (1970), in collaboration with the phenomenologist Edmund Husserl, wrote a dissertation entitled "On the Problem of Empathy". Stein described empathy as an experience "sui generis" or absolutely unique in its complexity. 
It is given to us "prereflectively" and unlike sympathy and other interaction phenomena, it is a "nonpremordial" experience. Stein stated that empathy unfolded in overlapping steps and when recounted was then given premordially (Davis, 1989). Stein further asserted that we never empathize; empathy happens to us. It "catches" us. Davis made an analogy to assist in understanding.

It is given to us much like true forgiveness; we can want to forgive, and try to forgive, but when the forgiveness finally comes, there is a sense in which we haven't done a thing except allow it to come. (Davis, 1989) Empathy in Psychology Literature

In her review of literature on empathy, Gould (1990) describes the works of the psychotherapist Rogers and attributes most of the studies done on empathy to his early work. Rogers' theory (1975) was based on extensive experience with clients during psychotherapy and counseling. Rogers' theory is concerned with facilitating the growth and development of human personality towards maximum potential. According to Rogers (1958), the ability of one individual to help another depends on the creation of a relationship fostering warmth, genuineness, sensitivity, and empathy. His definition of empathic behavior, now regarded as classic, is:

To sense the client's private world as if it were your own, without ever losing the "as if" quality. (Rogers, 1957).

Further research by other psychotherapists and counselors substantiated Rogers views. Buber (1955) challenged the views of Rogers, indicating that Rogers did not 
understand empathy. Writings by Buber attempted to distinguish the differences between self transposal and empathy. Self transposal was described as an attempt to think oneself into the place of another, to put oneself in the place of another by way of concentrated effort; to walk a mile in another's shoes, cognitively, in order to better understand the other. Empathy then was more than selftransposal; it had to do with a "crossing over" that takes place, wherein the person experiencing empathy seems to cross over into the other person's world of meaning.

Martin Buber (1937), in his philosophical work $\underline{I}$ and Thou, maintained that human experience may take two forms. The "I and It", referred to human interactions with objects, and the "I and Thou", referred to human interactions with humans or living things. Buber stated, "The man who experiences has no part in the world. For it is 'in him' and not between him and the world that the experience arises" (p.5). In clarifying the concept of "I - Thou", Buber stated, "the primary word I-Thou establishes the world of relation" (p. 6 ). The I- Thou experience is described as an "eternal form of art" in that the experiencing of this relationship is esthetic in nature. Buber's concept of "I - Thou" was often used in early empathy literature (Brown, 1990).

Gould (1990) asserted that as early as 1952, the psychologists Hartorf and Bender hypothesized on the evidence of early rating instruments, that empathy might constitute a multi-dimensional concept. Incorporated in this concept was objectivity, cognitive ability and the ability to understand how other people think. This view was 
shared by Taft (1955) in his review of 81 studies attempting to determine how individuals judge the feelings and behaviors of others. Deutsch \& Mandle (1975) pointed out that until the constructs comprising empathy are firmly identified, research results will remain of doubtful value.

The followers of Carkhoff (1969) conceptualized empathy as a communication skill that could be practiced for adequacy and accuracy. They suggested that empathy was an "accurate matching of the words and feelings of a person". Counselors, teachers, nurses, social workers and physical therapists were trained in the skill of empathy by grading their accuracy on a scale of one to five. The intended goal of the training session was to improve communication skills, and thus improve interaction and, ultimately, to improve therapeutic relationships.

Morse and colleagues (1992) described that in the 1950's Carl Rogers drew attention to the importance of empathy for counseling and developed techniques for client centered counseling. Following this work were efforts to determine empathic ability and develop empathy training program. Clark (1980) wrote of empathy as a neglected topic in psychological research. Gladstein (1984) encouraged the emotive, non-measurable components of empathy be addressed in research.

\section{Definition of Empathy}

A review of literature yields multiple definitions of empathy. Empathy has been defined as the taking of the role of the other, viewing the world as the other sees it and vicariously experiencing the other's feelings (Goldstein \& Michaels, 1985; Rogers, 1975; 
Zderad, 1969). Empathy implies being adept at reading the other's nonverbal communication and interpreting the others underlying feelings (Brown, 1990). Empathy is exuding a feeling of caring and sincerely trying to understand the other in a nonjudgemental and helping way (Goldstein \& Michaels, 1985; Rogers, 1975; Zderad, 1969). Triplett (1969) defined empathy as "a healthy form of identification which is limited and temporary but which enables one person to feel for and with another, to understand his experiences and feelings. The empathic individual possesses a warm capacity for projecting himself into the situations and feelings of others " ( $p$ 673).

Zderad (1969) asserted that the phenomenon of empathy can be further viewed and described differently dependent on the focus. This focus can be predominantly toward the psychological, physiologic and social dimension. The psychological process of empathy considers a subject - object fusion or the subjective state in which the empathy process culminates with the experience of the oneness with another. It is a feeling into the other person's thinking and feeling, his psyche, his situation and needs, his private world. Zderad further held that empathy results in an experiential knowledge of the other man for it is a sensing, comprehending, or sharing of his psychological state or internal frame of reference.

This empathic knowing can be distinguished from purely intellectual or theoretical understanding. It is often characterized as insightful, a kind of vicarious introspection. 
The view of empathy as a physiologic response may be described as a motor mimicry. The empathizer becomes so absorbed in the other person that there is an impulse to move in the same manner or assume the same posture of the observed person.

Zderad further described the social dimension view of empathy, This view is given prominence when the phenomenon is considered a process in which the empathizer takes another person's place. An example of this is the phrase "stepping into the other person's shoes". This implies not merely experiencing the same feelings but taking on the other person's view.

The descriptions of empathy presented up to this point have been unilateral. The focus is on the empathizer's state of relatedness, the feeling with the other, a subjectobject view.

Empathy has also been viewed as an intersubjective relating. The emphasis of this view is on the two subjects and their between. An example of this view is the notion of the I-Thou relationship described by Buber. In this view empathy is a process of intersubjective relating as seen in human encounters and genuine dialogue. Zderad described an attitude of receptiveness, availability and presence as prerequisites.

Several concepts also imply similar kinds of human movement as empathy. These concepts are at times mistakenly used to refer to empathy. Each of these concepts can be distinguished from empathy. Brown (1990) clarified and defined these concepts in an attempt to render an explanation on the concept of empathy. One term is sympathy. Sympathy is described by Zderad (1969) as "empathy plus" (p 658). 
Sympathy is characterized as feeling "with" rather than "through" the other. Sympathy connotes pity, condolence, and the acceptance of the others' values about the feelings experienced. When one sympathizes, there is no therapeutic attempt of the experience, as one becomes subjectively involved (Goldstein \& Michaels, 1985; Zderad, 1969).

Identification is a term used to indicate that one person assumes the attitude of another or imposes his own attitude on another (Zderad, 1969). Projection is another concept related to empathy. Projection denotes the attribution of one's own attitudes or perspective to the other. Identification and projection refer to processes of subject object fusion. In this way, these concepts are similar to empathy. They differ from empathy in that the distinction of the individuals relating is lost. In empathy, the recognition of the distinction of the individuals is necessary.

\section{Empathy in Nursing Literature}

There has been and continues to be considerable interest and controversy in the nursing literature surrounding the concept empathy. Emergence of empathy in nursing literature paralleled the empathy research in psychology.

In the 1950's empathy appeared in the nursing literature (Morse et al 1992). Peplau (1952) introduced the term empathy to nursing to describe the natural process by which maternal emotions are transmitted to infants. In 1957, Rogers delivered a keynote address to the American Nurses Association on the essential characteristics of a therapeutic relationship. Nurses then began to examine the concept of empathy and it's application to nursing practice. Holliday (1961), Travelbee (1963), Triplett (1969) and 
Zderad (1969) contributed works (Morse 1992). These early works embraced Rogers concept of client centered therapy.

This early literature called for a greater awareness of empathy and its therapeutic value in patient care. Proposed at this time was a need for developing empathy in nurses (Zderad, 1969; Kalish, 1971; LaMonica, 1978). Southerland (1993) describes conflicting viewpoints expressed by other authors. These authors questioned the value of and even the existence of the phenomenon of empathy. Norris, in an article entitled "Delusions That Trap Nurses", denied the existence of empathy or caring in nursing. She stated “... nurses have not been able to deliver this bounty (empathy) in any consistent way to any sizable group of patients" (Norris, 1973, p.19). Morse (1992) suggests that empathy is actually a poor fit for the clinical reality of nursing practice.

Southerland (1993) found that at the core of this controversy is confusion about the concept of empathy. Empathy has been termed an ability, an attitude, a feeling, an interpersonal process, a trait, a state, a sensitivity, and a perceptiveness. This ambiguous use of the concept has impeded isolation and examination of empathy in nursing (p. 369).

The term "empathic resonance" was introduced by Geach and White in 1974 as the process of sensing the feeling states in patients who are unable to communicate in "ordinary" ways.

Morse and colleagues (1992) described the debate in nursing literature that centered on the balance between subjective and emotive involvement with patients and a 
more objective/professional stance thought to be necessary. The outcome of this debate devalued sympathy and promoted empathy.

Travelbee (1963) believed that both compassion and sympathy had a place in nursing practice. Kalish (1973), Triplett (1969), Zderad (1969), Bradley \& Edinberg (1982) and Holden (1990) devalued sympathy as sentimentality and promoted empathy as a more professional approach. Morse (1992) proposed that because the difference between sympathy and empathy was unclear, the acceptance of empathy could be interpreted as an attempt to professionalize nursing practice.

The development of nursing theories included attempts to clarify and legitimize empathy in nursing. Works by Zderad (1969), Forsyth (1980), La Monica (1978), and Kalish (1973) are some authors who contributed to the emerging empathy literature. Sanchez (1989) and Wheeler (1988) incorporated empathy into extant nursing theory. La Monica (1983) and Burgess (1990) produced works with the goal of modifying psychological models of empathy to fit the nurse-patient relationship.

Zderad (1969), in her humanistic nursing model, stated that empathy was an essential part of therapeutic communication. Zderad identified a three-phase model of empathy. The initial phase consisted of an assessment of the inner world of another. The next phase was concerned with facilitating an interpersonal relationship that would enhance the well being of the other. The third phase of (clinical) empathy Zderad described as a detachment phase. This phase removed the nurse from the risk of personal involvement and kept the interaction professional. Zderad in this model focuses 
on the actual movement from a subjective experience through to an objective cognitive analysis.

Wheeler (1988) did not embrace a multiphase model. Wheeler's model of empathy was based on Martha Rogers systems paradigm of nursing science (Rogers, 1970). Within this framework, empathy is seen as a mutual simultaneous exchange. The exchange is considered to occur within a cosmic matrix of human and environmental energy fields.

\section{Empathy Measurement}

Empathy has been identified as a critical component of nursing. It is seen as the central "helping component" in nurse - patient interaction. Thus it is theoretically important to determine a nurse's empathic ability and level of empathy. As stated earlier, empathy is highly subjective. The subjective nature of empathy is difficult to determine with a measurement instrument. A number of tools have been developed by researchers to determine empathy measures.

In the last two decades, nurse researchers and educators have attempted to measure empathy (Kalish 1971, LaMonica 1981, 1986, Layton 1976). The instruments and observation schedules, although developed by nurses, are grounded in social/counseling psychology (Morse, 1992). Morse (1992) outlined the attempts of nurse researchers. Research has attempted to: (a) identify nurses characteristics and actions that differentiate empathic from non-empathic nurses (Forsyth 1979, Stetler 1977); (b) identify factors that are related to nurses' ability to empathize (Brunt, 1985; 
MacDonald, 1977; Mynatt, 1985; and Rogers, 1987); (c) identify behaviors that facilitate empathic communication in nurses - patient interactions (Mansfield, 1973); (d) evaluate nurses functional levels of empathy (Hills \& Knowles, 1983; Pluckman, 1978); and (e) evaluate the effectiveness of empathy training programs (Kalish, 1971; LaMonica, Carew, Winder, Hasse \& Blanchard, 1976; LaMonica, Madea \& Oberst, 1987; and Layton, 1979).

The results of these studies are inconclusive and difficult to compare due to methodological inconsistencies. These inconsistencies include lack of statistically derived inter - rater reliability coefficients, lack of valid empathy scales for use with nurses and patients, and lack of comparability between individual researcher - developed empathy training program (Morse, 1992).

Morse (1992) proposed that an obstacle to understanding empathy is the attention of researchers to measure the observable, objective components of empathy. The subjective non-measurable components have been ignored. Research by Kalish (1973) and Kurst-Wilson, et. al. (1981) captured the cognitive component of empathy. The emotional component, the nurse's ability to identify emotionally with patients, has not been given attention by researchers.

There are currently three groups of instruments designed to measure empathy. The first type of approach is the self-rating scale. This was designed by LaMonica in 1981 and is called the Empathy Construct Rating Scale (ECRS). The second type of approach is a rating by expert judges or colleagues. Examples of this are the Hogan 
Empathy Scale (1969) and the Accurate Empathy Scale (Truax 1961). The third type of approach is the client/patient rating. Two examples of this are the Carkhuff Helpee Stimulus Expression (1969) and the Empathy Subscale of the Barrett-Lennard Relationship Inventory (BLRI) of 1962. With the exception of LaMonica's ECRS, the other instruments were developed by authors of academic disciplines other than lnursing. Scales devised by therapists for clients in psychotherapy may be inappropriate for assessing empathy within the nursing context, as these disciplines are not the same.

The relationship between client and counselor is different from the relationship between client and nurse. Many clients depend on the nurse for physical care and have contact with the nurse for a prolonged concurrent number of hours. Clients in counseling do not typically depend on the counselor for physical care or spend prolonged concurrent hours with their therapist.

There have been attempts to determine elements of the empathic personality. Sparling and Jones (1977) demonstrated no differences in empathic ability according to age, marital status, level of education or length of nursing service using the Carkhuff Helpee Stimulus Expressions but found that nurses working in a psychiatric setting were significantly more empathic than other nurses. Forsyth (1979) failed to show that nurses in a psychiatric setting were more empathic, but by using the Hogan Scale and BCRI found a trend of increased empathy among married nurses and those in the profession for more than two years or less than six months. MacDonald (1977) found that men in nursing show more empathy than women. 


\section{Teaching Empathy}

There is considerable agreement in the literature that empathy is a human potential, which must be developed and not left to chance. Aspy (1975), a counseling psychologist, spoke of his belief that our entire society would benefit from learning the application of empathy to human relations. He recommended that empathy training be a part of every service oriented profession. Rogers (1957) thought that empathy is best taught by being around other empathic persons. He believed that being in an empathetic climate itself teaches others to be empathetic. Others have suggested that empathy be directly taught as a skill just as other skills are taught.

Gazda (1987) developed a Human Relations Training Model. A respectful attitude was considered a prerequisite for obtaining the skills necessary for communicating empathic understanding. Developmentally, to be empathic, individuals must have reached a stage where they have sincere interest in another, they must have matured beyond thinking of themselves, so they can be capable of understanding another's point of view. Different groups of studies have examined attempts to enhance empathic ability through teaching, role play and other experimental techniques. Alverson (1987) showed films about interviewing techniques followed by discussion. In a study by Kalish (1971) the same individual would teach and then act as evaluator of the process. A study by Peitchinis (1972) examined nurses' therapeutic effectiveness during counseling, utilizing Edwards Personal Preference Schedule and other tools. Empathic ability was then compared with results gleaned from standard personality tests. The 
findings showed that nurses scored poorly on qualities traditionally associated with therapeutic effectiveness but were aware of their limitations and made genuine attempts to overcome them.

Hourard (1971) found that anxiety operates as a barrier leading an individual to develop a protective shell preventing both the expression of feelings and the recognition of distress in others.

In studies by Stockwell (1972) and Podrasky \& Sexton (1988), nurses acknowledged that they disliked particular patients. These patients were different from themselves. Patients who are of a different culture, religious persuasion and social class seem poorly understood. Further evidence that nurses are best able to empathize with people on the basis of shared experience is provided by Holm (1989). A questionnaire study involving 205 nurses showed that understanding of the patient in pain was greatest among nurses with personal experience of pain.

Forsyth (1989) continued to examine whether caring behaviors can be taught. The nonverbal elements of empathy were identified as nods of understanding, facial expression congruent with content of conversation, tone of response similar to clients, full attentiveness to deeper meaning of client's responses, and understanding of clients internal frame of reference.

Morath (1989), in her work with empathy training, stressed that empathy is especially important in dealing with persons in stress. People under stress respond to a feeling more than the content of the messages. 
In general, the results of studies of empathy are inconclusive and difficult to compare due to methodological inconsistencies. There remains a lack of valid empathy scales for use with nurses and patients and a lack of demonstrated construct validity of the concept in the health care setting. Increased attention must be paid to concept specification prior to the development of scales to measure empathy. Once the concept of empathy is thoroughly understood in the nurse/client context appropriate empathy scales can be developed. 


\section{CHAPTER 3}

\section{METHODOLOGY}

\section{$\underline{\text { Design }}$}

A descriptive, exploratory qualitative phenomenologic approach design was utilized for this study. This approach allows for an emphasis on the meaning of a lived experience (Beck, 1994). According to van Manen (1984) the experiences and reflections of others are "borrowed" so that the researcher is able to understand the deeper meaning or significance of an aspect of human experience. The aspect under study was empathic interactions.

The target population for this study included nurses and clients in an acute care setting within a metropolitan 1800 bed medical center in the southeast United States. Nurse and client participants were selected from general adult medical and surgical units within the hospital. Subjects were English speaking.

A purposive sample of clients and nurses was selected. Nurse managers on the patient care units were contacted to nominate nurses on their unit for possible participation in this study. Nurse participants then nominated clients they had cared for who were willing to participate in the study. Eight nurses and seven clients were interviewed once consent had been obtained. To be eligible, nurse participants had to be full time employees with permanent status on the patient care unit and were willing to participate. Persons excluded were those not desiring to participate. The criteria for client eligibility were that the client be of adult age, be an inpatient for at least three days 
, and have been cared for by one of the nurse participants at least twice. Persons excluded were those not desiring to participate.

\section{$\underline{\text { Setting and Sample }}$}

The setting for this study was an acute care unit within a 1800 bed metropolitan medical center serving a culturally and ethnically diverse socioeconomic client mix. Participants were recruited from general medical/surgical patient care units within the hospital. The setting for the interviews was a room free of distractions on the hospital campus. Once consent was obtained, a time for the interview was scheduled at a mutually convenient time for both the interviewer and the participant.

\section{Measurement Tools}

Semi-structured interview guides developed by the investigator were used to explore empathy. Separate interview guides were prepared for nurses and clients (Appendix A). These interview guides had been pilot tested on two nurses and two clients to determine understandability and approximate interview duration time. The pilot tests did not reveal the need to revise the interview guides. Broad, open-ended questions were used.

\section{Protection of Human Rights}

Eligible study subjects received a letter inviting them to participate in the study. The letter provided information regarding the purpose and nature of the study as well as the rights of participants in the study. The interviewer's name and telephone number was provided to the subjects to enable them to have any questions answered. Both nurses 
and clients were assured of anonymity and confidentiality (Appendix B). Anonymity was ensured by giving each subject a code number. A master list of the subjects' names and code number was kept in a locked cabinet by the investigator. All instruments and forms completed by each participant as well as the transcribed interview question session were identified with the assigned code number. The signed consents were kept in a separate location from the code numbers to assure anonymity. The raw data were entered into the computer using the code numbers for identification. Every effort was maintained to ensure confidentiality of the participant's identity. Participants' names were not used in reporting while the content of the interview is unchanged. Efforts were made not to mention the subjects' name on tape.

\section{$\underline{\text { Data Collection }}$}

Contact with nurse managers of general medical/surgical units yielded nominations of nurse participants. These nurses in turn nominated clients for possible participation. Eligible nurses and clients were invited to participate in this study through a letter (Appendix B). The letter to the nurse participants was distributed by the investigator through the inter-office mail system or by hand delivery. The destination of the letter was the patient care unit of the nurse participant. The letter to the client participant was delivered directly to his or her room in the hospital. Participants were requested to sign a letter of consent prior to their participation in the study (Appendix C). The investigator followed-up to determine if the consent had been signed within 
twenty four hours. Upon completion of the consent, the interviewer and participant agreed on a time and location for the interview.

Face to face interviews were conducted. The interviewer met with the subjects and used a semistructured interview schedule. The interview was tape recorded verbatim and then transcribed by the investigator for analysis. Since the focus of this study was on empathy, a distinction was made suggesting the difference between sympathy and empathy. A definition of empathy was reviewed in the course of the interview. The interview started with the interviewer asking the subject a series of questions to guide the interview. Additional prompting questions such as "Does that make sense to you?" "Do you agree?" "Is that a distinction you would make?" "Had you thought about that?" were asked. Once there was an agreed-upon differentiation between their experiences, the interviewer focused directly on empathy. The initiation of this conversation with a nurse consisted of a statement like "I'm so glad you see the distinction, because today I would like to focus on empathy." The initiation of the interview with a client began with. "So, you do see the distinction between sympathy and empathy."

Data Analysis

Unstructured data were generated from the interviews.

The interviews conducted with both the nurses and clients were tape recorded, then coded by number, and transcribed verbatim by the researcher. Quotations from nurses and patients were reported verbatim, with the exception of such phrases as 
"like," "you know," and "umm". Subjects were distinguished by their code numbers, with a "N" indicating a nurse quote and a "Cl" indicating a client quote. The researcher then replayed the tapes and compared with the typed transcription to verify completeness and accuracy.

All of the taped interviews were transcribed into individual protocols for each subject. Once transcribed, the interviews were printed allowing for double spacing of text (Appendix E).

Transcriptions were additionally verified for accuracy by a nonparticipant listening to the interview while reviewing the transcription. No discrepancies were found.

The procedure to analyze the responses should have been content analysis. Content analysis begins to categorize verbal data (Burns \& Grove, 1987). Both semantic content analysis, the counting and coding of responses, and inferred content analysis are indicated. Inferred content analysis went beyond what was said directly to infer the meaning. Analytical induction should also completed.

The phenomenological analysis of the data technique used by the investigator in this pilot study was that of Colaizzi (1978). This technique has been used previously in at least 14 phenomenological studies. The Colaizzi method was selected for the focus on the meaning and essence of experience. The investigator attempted to gain a fresh perspective of the phenomena of empathy that would provide insight and understanding 
of how clients and nurses view empathic interactions. This technique consisted of seven steps.

1. Reading all of the subjects' descriptions.

Once transcribed, each of the written description protocols were read several times to allow the investigator to have a sense of their content and acquire a feeling tone (Appendix E).

2. Extracting significant statements.

The investigator read the written protocols and extracted phrases and sentences that directly related to empathy. These phrases and sentences were underlined on the written protocols and maintained verbatim. Repetition of the same phrase or sentence by the subjects was not repeated. Underlining the significant statements served to ease visual recognition of the statements for the next step. A list of the phrases and statements was typed (Table $1 \& 2$ ).

3. Creating formulated meanings.

The next step consisted of color coding the significant statements according to a topic. Color coding served to make manageable the large quantity of interview transcripts for easier recognition visually. Color coding of topic headings for the client significant statements was also performed.

The protocols and significant statements were then reread in an attempt by the investigator to create a meaning to the statement. The investigator ascertained the underlying meaning of the statement. The total context of the protocol was considered. 
The formulated meanings and the corresponding significant statements that led to the meanings are listed in theme clusters in Table $3 \& 4$.

A colleague who is an expert in research read the protocols and then read the formulated meanings determined by the investigator. This colleague agreed with the themes in the description and verified that the reflections related to each other. In phenomenology inter-rater reliability is not necessary since the work is the essential reflection of the phenomenologist. The phenomenologist validates his or her own experience (Ray, 1996).

4. Aggregating formulated meanings into clusters of themes.

The subsequent step in analysis was to configure clusters of themes that were common to all of the protocols (Table $3 \& 4$ ). These clusters of themes were also reviewed with the same colleague who had read all of the protocols. In this process, contradictory statements would be reexamined. There were not any contradictory statements or discrepancies noted.

5. Writing an exhaustive description.

The investigator then wrote a narrative exhaustive description which united the significant statements, the formulated meanings, and the clusters of themes (Table $5 \&$ $6)$.

\section{Identifying the fundamental structure of the concept.}

The investigator then wrote a statement of the fundamental structure of empathy. The source of the fundamental structure was from the exhaustive description of the 
phenomenon of empathy. Tables $7 \& 8$ capture the fundamental structure of empathy as described by the investigator.

7. Returning to the subjects for validation.

The investigator returned to five of the nurse subjects to validate the results of the analysis. All of these nurse subjects agreed with the analysis and expressed their opinion that it captured their experience. One client subject was available for validation and did concur with the study findings. The investigator did feel that based upon the spontaneous comments made by the client subjects immediately after the taping, the results did capture their experiences.

The use of the Colaizzi method of data analysis ventured beyond noting the frequency of mention of a subject to an evaluation of what factors appeared to contribute to the phenomena. 


\section{Chapter 4}

\section{Results}

In this chapter the findings of the study will be reported. The data analysis process for this qualitative study was fluid and ongoing.

Demographic Profile of Sample

Eight nurse subjects and seven client subjects agreed to participate in this study. All of the subjects met the study criteria for eligibility. The nurse participants ranged in age from twenty-nine to fifty four years. All were female. Male subjects nominated for participation did not agree to participate. The range of years of nursing experience for the nurse subjects was from six years to thirty one years. Areas of specialization of nursing practice included medical, surgical, oncology, and critical care. Six of the nurse subjects had themselves experienced hospitalization. Reasons for hospitalization included childbirth, surgery and medical evaluation and diagnosis.

The client subjects ranged in age from thirty four years to sixty five years. There were three male clients and four female clients. All of the client subjects had previous experience of hospitalization. Reasons for past hospitalization included; leukemia, diabetes mellitus, childbirth, asthma, surgery, chemotherapy, and diagnostic evaluation. The client level of educational achievement ranged from incompletion of high school to college graduation. 


\section{Protocol Reading}

The initial step of the content analysis, reading the protocols, demonstrated both similarities and differences between the two subject groups. The similarities were found in the descriptions of aspects of empathy between the two subject groups. Both nurses and clients used affective and sensory terms. The differences included the contrast in the abstract descriptions of the aspects of empathy. Nurses tended to use more abstract terms and elaborate more. Clients used more simplistic language that was brief and to the point. An example of the differences follows:

N03: (Empathy) "It is a state of grace. A moment in a connection with a person when the rest of the world stops. You only are aware of what is happening at that moment with the person you are with. Sometimes you feel what the other person must be feeling. Othertimes you don't know what they are feeling, but you do feel like you are right with them, every step of the way at that moment. It is hard to explain. You know, it is like it is more of a sensation, a feeling. Not so much a thought."

CL01: "I think empathy is a feeling for another person. Having feeling for them."

The subjects' definitions compared with the definitions of the experts as described in Chapter 2.

\section{$\underline{\text { Significant Statements }}$}

The second stage consisted of extracting the significant statements (Table $1 \& 2$ ). The nurse and client subjects were able to clearly articulate their perceptions of empathic 
interactions. A review of the significant statements of Nurses (Table 1) and Clients

(Table 2) reveals an example of the congruency between the two subject groups.

Table 1 \#14 "You place yourself in the place of the other person, to try to figure out how they are feeling."

Table 2 \# 39 "To try to understand my feelings."

Formulated Meanings

The significant statements were read to spell out a meaning of the statements.

The underlying meaning of the statements was developed. Clusters of themes aggregated from the formulated meanings were gathered for both the nurse subjects (Table 3) and client subjects (Table 4). A review of the themes reveals that both the nurse and client experience of an empathic interaction is involved and all encompassing. There are more similarities than differences in these findings. There were twelve facets of themes compiled from the nurse and client formulated meanings. There are common experiences in empathic interactions as felt by both the nurse and client. Findings related to the identified themes will follow.

Nurse subjects focused on the sense of connection between the persons involved in empathic interactions. This was described as;

"The moment when you really connect."

"A moment in a connection with a person when the rest of the world stops."

"Finally, when I stop what else I am doing, then I may feel the energy as I feel more connected and attentive of the person and not the task." 
Client subjects did not focus on the word connection. The perception of a sense of being cared for by the nurse was described by the client subjects.

"I think it is when someone really cares about someone else."

"They care about how you feel."

"You know that they care."

Active listening was felt by both subject groups to be associated with empathy.

The many methods of active listening were described commonly by both subject groups.

This was verbalized emphatically by nurses as:

"It's listening to what they are saying and 1 etting them know that you are really hearing what they are trying to get across to you."

"It might be just listening, just listening alone is a big part of it."

"Listening, even to the silence between us."

"There is an urge to listen more. An urge to reach out."

Clients described the active listening on the part of the nurse as:

"She could listen to you."

"By listening well to your concerns."

Through the responses of both the nurses and the clients it was clear that empathy is associated with a sense of focused attention. Nurses described focusing attention on the process occurring between the two individuals as:

"It's being totally there, just strictly focusing on what they are saying." 
"It's not letting outside distractions take even a minute of your time away from them."

"You can help them go towards these things in a way that is meaningful to that person."

"A moment in a connection with a person when the rest of the world stops."

"You are only aware of what is happening at that moment, with the person you are with."

Woven through the statements were descriptions of clear focus individually on the client, free of distraction.

The clients described the focused attention in terms of an assessment by the nurse of specific individual needs;

"They try to find out how they (client) are."

"They try to find out what you need."

Mention was also made by the client of the concept of a freedom from distraction as follows:

"Their facial expression, their gesture, whether they are concentrating on me." "Their mind is not away."

Nurse subjects focused on the element of a response to meet the individual needs of a client. This was described in ways such as:

"Trying to grant the request of the client." 
"The need to prioritize the relationship at that time, whatever needs to be done for the patient."

"A sense that I need to commit my time at that particular time to that individual."

"We do things for the individual because there is a reason and there is some kind of emotional attachment."

Clients also described the individualization but it was incorporated into other themes such as active listening, feeling cared for and remembered.

The sense of presence was a theme that was revealed by all of the participants.

It was expressed emphatically by nurse subjects in the following responses:

"They feel that you are really there for them."

"Once again it's just being present, just a feeling that I am here for you."

"It's someplace you place yourself."

"You place yourself in the place of the othe $r$ person, to try to figure out how

they are feeling."

"My being there."

"There is a presence and you know directly that something is happening."

Client subjects described a more physical presence as:

"She could stay in your room for a while."

"One nurse always came in to see me."

"Just being there." 
"They just sit by me."

"Stand with you and be supportive of you."

In contrast to the above concrete description of a physical presence is the more abstract description of client subjects;

"They are wi th you in different ways."

"An ability to be available to somebody."

"To be willing to be available and open."

Energy was a theme that was described by both subject groups. Question \#4 for both subject groups inquired about the sense of energy being exchanged. For both of the respondent groups the use of the word energy was not articulated prior to the answering of this question. Subjects did speak of empathy in direct energy terms. Energy may have been implied though in the use of a few of the subject's choice of the word "bond" in responding to earlier questions. Interestingly, most of the subjects, especially the nurses, latched on to this concept of energy once it was introduced, immediately agreeing that it is a component of empathic interactions. Two client subjects denied having felt a sense of energy exchange in previous processes of empathy. The concretization of the concept of energy was focused on as a bond. Energy was then referred to again in the responses to subsequent questions. Nurses associated empathy with both an awareness of a change in energy and a description of the energy as a bond. The awareness of empathy as a change in energy was described repeatedly as follows; "I felt that it left me with something. It definitely affected me." 
"It's almost magical. Looking back a very magical moment."

"You are taken to a different plane."

"They are on the same wave length."

"It is powerful. It must be the energy."

"It's a back and forth feeling."

"Something happens. You feel the connection of putting yourself in the person's place."

"You can't describe it in words, it is the feeling, a wave inside you."

"Something above and beyond just communicating."

"It can be a bit overwhelming, it becomes evident that there is an exchange."

"There is something that shifts in me. There is a move. An emotional drive."

"It is always with me."

Nurses consistently used the word bond in describing energy as represented in the following responses;

"You can feel a certain bond with a perso n."

"The bond can also energize you."

"The bond feels like you are touching base with someone. It's more than just physical."

"It is a special bond that you are aware of."

"It's a strong bond." 
The clients described energy more as a sense of sharing as described in the following statements;

"Feel whatever you are feeling."
"You are somehow sharing a bond of energy."
"There is a definite energy that is part of that."
"Doesn't take anything away from anybody."

A theme specific to the nurse subjects was the idea that empathy is infused in nursing as an essential component. Question \#7 inquired, asking how empathy is a part of nursing. Responses by all nurses indicated that empathy is an essential component of nursing. N 01 described it as follows;

"I think empathy is probably the biggest part of nursing. Unfortunately, you are not given a lot of time. How can I put this? I think empathy is the biggest part of nursing, it's probably good it's not a conscious effort or it wouldn't get done half as much as it should get done. Empathy is every part of nursing. As soon as you meet a person, when you are trying to, it's just every part of nursing, everything you do. The first words you say to a person, if you expect them to be receptive to any teaching that you might want to do, or to take part in their own care, they have to know that you are really, you are a big motivator for them and to me it (empathy) is the key to everything you do with that person. It's how they look at you, and how they are going to respond to whatever you may do for them." 
N 08 chose these words for her response. "Empathy as part of nursing, I think really, should start. It should be an innate factor within the individual nurse. I think the profession would probably, should promote a deepening of that, and I think for the nursing profession, it should become. It should start with understanding.

Communicating this understanding to the client. Whatever day to day activities are being done for the client it has to incorporate some component of empathy. That is, to be sure it is not just routine work. That we do things for the individual because there is a reason and there is usually some kind of emotional attachment to each task. From talking about this, answering these questions, it is interesting. I am transposed back to past experiences. Each question I can relate to some kind of experience I have had and it really is not within the same scope. It is usually with different practices. There is always a reference for me. It is always with me. These questions have really evoked the reality of what has probably just been dormant, waiting to be expressed."

Nurses also spoke of a self transposal and resonation with the experience of the client. These phrases were used for description:

"You place yourself in the place of the other person, to try to figure out how they are feeling."

"You see things from their perspective."

“Something happens. You feel the connection of putting yourself in the person's place." 
The spiritual dimension of empathy was described by one nurse as a state of grace. Touch was described as a way of expressing empathy both by nurses and clients in their responses. Phrases used by nurses to describe this were:

"You touch them if that's what they need."

"By holding the patient's hand you and convey, just stand by the patient, hold their hand."

"With a touch I can convey."

Clients chose these words to describe how empathy is facilitated by touch.

"By touch, you know by holding your hand."

"Touch you, just hold your hand."

"Put their arms around me."

"They may just put their hand on yours."

The use of the word "just" seems to infer a simplicity of action.

The deliberative nursing process, a process of identifying the real needs of a client and then deliberately selecting an intervention specific to the clients needs, was mentioned numerous times by nurses as being a part of the empathic process. Short examples of remarks describing this follow;

"Trying to grant the request of the client."

"The need to prioritize the relationship at that time, whatever needs to be done for the patient." 
"A sense that I need to commit my time at that particular time to that

individual."

"We do things for the individual because there is a reason and there is some kind of emotional attachment."

Clients emphasized more on a sense of focused attention as described earlier. Clients did speak of empathy experienced with a sense of being treated holistically. This was described as " that my whole person was being treated." Theme Clusters

The fourth step, aggregating formulated meanings into theme clusters (Tables 5\&6) reinforced the congruency between the two subject groups work. There was clear emergence of common themes in the subjects transcribed interview protocols. Again the nurses had more numerous clusters, but the content was similar.

Exhaustive Description

Tables $7 \& 8$ captured the next step in the process of data analysis. This is the exhaustive description of the concept of empathy. The results of the earlier steps were integrated to form this description.

\section{Fundamental Structure}

The sixth step identified the fundamental structure of empathy. The fundamental structure of empathy from the nurse and client perspective will follow. This study found that empathy as perceived by nurses is experienced as a connection with an individual when there is an awareness of a change in energy between the two. Concretization of 
this concept of energy is described as a bond. Empathy is a process that unfolds in an environment of active listening, authentic presence, focused attention and touch.

Empathy involves attempts to meet the individual needs of the client. The process of empathy is accompanied by an understanding of the other and a sense of self-transposal and resonation with the experience of the other. The experience of empathy is felt to be an essential component of nursing.

Empathy, as perceived by this group of hospitalized clients, is experienced when there is a sense of presence of the nurse. The client associates empathy with feeling cared for by the nurse. Active listening, an awareness of nonverbal communication and the use of touch by the nurse contribute to the sense of sharing the process of empathy. A sense of feeling understood and even remembered from past experiences is a part of the empathic process. Empathy is associated with a sense of being cared for individually in a climate that focuses attention on your own specific needs. It is sensed that the nurse transposes self and in that process an energy is shared. This experience of empathy leads to a sense of being treated holistically and even a sense of enhanced well-being.

The investigator made notes of sensory observations after the interview sessions and the subjects had departed. Common themes surfaced. Once the last question was answered and the tape recorder was shut off, the subjects were thanked for their participation. In return, the subjects described how they had enjoyed the process. The nurse subjects each talked at length about how meaningful the interview session was. Of note is that each of these interviews occurred on the subjects' own time, often after a full 
eight or twelve hour shift. The nurse subjects did not seem to have any intent to leave the room promptly. Rather, there seemed to be an intention to remain. Of note also was a gentleness of speech tone once the recorder was turned off. There seemed to be a special reverence for the subject. Subjects spoke of gratitude for the opportunity to reflect on empathy and its meaning. One nurse spoke of a realization that by discussion and recall she had a newly realized strong sense of the transformation that takes place in empathic interactions. She spoke of a realization of being changed by each encounter whether you realize it or not. She stated, “it's always with you. You are never the same." As she spoke her hand emphasized her feelings with a gentle motion over her chest about four inches above the surface of her clothing. This same motion was observed more frequently than not when the subjects both nurse and client spoke of energy and the bond of connection that is felt. After the tape recorder was turned off, a client reflected on the discussion and related a new feeling of hope that she had become aware of. She stated, "Empathy gives us hope. You may be lonely and you may be scared -- but empathy lets us know that someone cares to bridge the gap."

Another observation worthy of note in the nurse subjects was a deep look of the eyes and intense concentration when describing empathy and how it is a part of nursing. This deep look did not seem to be simply eye contact but an experience of looking deeper and beyond the eyes, nodding as if in self agreement once the words were found. Perhaps the nodding was an affirmation of the awareness of deepness of the subject. It may have also been a simultaneous shared insight of recognition, knowing the 
separateness of each other but also the possibility of shared encounters. It may have been the essential self that crosses over and merges in each one of us.

In the process of interviewing, the investigator experienced a strong sense of gratitude and honor to be a part of the process with the interviewees as they shared their perspectives. There was witness of the struggle at times of clients to find the words that they were searching for. There was a strong sense of an intent to be as honest as possible.

This qualitative, study allowed the investigator to enter the world of the nurse and the client and gain some understanding of their views. 


\section{Chapter 5}

\section{Discussion}

The intent and purpose of this study was to describe patients' and nurses' perceptions of the empathic process. Subjects of this study provided their perceptions of empathic interactions. The study findings provide a fundamental description of empathy as perceived by this sample of nurses and clients. In nursing practice, there is now an internal perspective of the phenomenon of empathic interactions. Tilden, Nelson and May (1990) suggested that increased attention be paid to concept specification prior to development of measures. This research can assist in future development of valid instruments to measure empathy.

\section{Conceptual Framework}

The conceptual framework utilized for this study was that of Martha Rogers (1990). Martha Rogers supported the view of nursing in a holistic manner to provide that the whole individual be treated, not just the disease process or pathology. Rogers viewed persons as unitary beings and irreducible wholes that cannot be understood by just examining components or subsystems. Table 2, Significant Statements- Clients, \#63 "that my whole person was being treated" provides evidence of the client's perception of a holistic manner of care as a component of empathic interactions.

Rogers also viewed each individual as a distinct energy field that is dynamic. The open nature of these fields allows for a constant flow of energy between the fields of different individuals. Nurses and clients both described empathy as being associated 
with, and awareness of, a change in energy. The following are examples of articulations that support this concept of energy; Table 3 Nurses \#25 "It is powerful. It must be energy." \#37 "It is a back and forth feeling. You can't describe it in words, it is a feeling, a wave inside you." \#56. "It can be a bit overwhelming, it becomes evident that there is an exchange." Table \#4 Theme Clusters - Clients \#51. "You are somehow sharing a bond of energy." \#59. "There is a definite energy that is part of that."

These statements support the theories of Martha Rogers. Common threads through the transcribed interview protocols were mention of a holistic approach and the concept of energy. Once the concept of energy was introduced, it was grasped on to and then referred back to numerous times throughout the interviews.

Reviewing the results of the analysis brings to mind the work of Buber (1955) and Zderad (1969). As described in the literature review, both Buber and Zderad viewed empathy as a process of intersubjective relating. The emphasis is on the two subjects and their between. Buber referred to this as the I Thou relationship. Zdered (1969) described an attitude of receptiveness, availability, and presence as prerequisites. The findings of this study clearly support the work of Buber and Zderad. Zderad's themes of receptiveness, availability and presence are reflected in this study's themes of focused attention and presence.

The works of Buber (1955) and Stein (1970) spoke of these interactions. This description of empathy by these nurses is more than self transposal. There is described a 
"crossing over" that takes place, wherein the person experiencing empathy seems to cross over into the other person's world of meaning.

\section{Implications for Nursing}

The meaning of empathy that unfolded in this study has implications for the various domains in nursing. There are significant implications from this study for nurses and the profession as a whole. These implications are widespread and include the dimensions of clinical practice, education, administration and research.

In nursing practice, there is now an internal perspective of empathy as experienced by both these nurses and clients that is foundational to practice. The findings of this study support the value of empathy in nursing practice. The value is held by both nurses and clients. The client and nurse subjects were both able to eloquently describe this experience of empathy in their interactions.

One nurse clearly articulated how the process of empathy restores energy. The understanding that empathy supports and restores energy may provide a new way to view empathic interactions. Empathic processes may be seen as a way of being in nursing that supports and restores energy. It may be seen as a self-care measure. It has been reported that nurses may maintain distance and avoid establishing empathic relationships due to fear of becoming "too involved and drained". These findings support the reverse notion. Empathic interactions may restore energy and increase the sense of satisfaction with the profession of nursing. Nurses need not lose their therapeutic objectivity as some fear, in getting "too close" or "too involved" with their 
clients. In empathy the holistic listening can unite the nurse with the client. The two are united but also separate in the encounter. This study has provided a new view of this perspective.

Woven through many of the descriptions was the awareness of time as being a factor in the process of empathy. Mention was made of the brevity of time required, "even just for a moment." It has been suggested by Morse et al (1992B) that with the increasing demands of clinical practice, empathy may not be a "good" clinical fit, due to the perceived time requirements for the process. The findings of this study demonstrate that empathy does not necessarily have to be time intensive. Descriptions supported that what was more important was the focus during the time of the interaction. The focus, understood to be empathic, was that the nurse would be present and attentive to the client as an individual with unique needs. Adequate staff support on the patient care units is necessary to aid the sense for the client of being treated holistically and as an individual with unique needs. Budget constraints are a reality in clinical practice. Nurses must continue to demonstrate and document nursing interventions which are both economical and effective.

The implications for nursing education are also abundant. It is important that empathy be integrated into the curriculum initially. Nursing educators can role model for their students the value of empathy for the clients as well as themselves. Nursing students, who early in their careers have the experience of observing and experiencing the high degree of both energy and personal satisfaction gained from empathic 
interactions, perhaps will not consider that empathy should be avoided. It is inferred in some of the responses that empathy is not something you are taught. It is a developmental process which could be guided by nursing faculty. Empathy is not exclusive to the nurse - client relationship, it is a human process. Any empathic interactions could serve as modeling. The interactions of faculty with students and faculty with clients could facilitate the appreciation and development of empathic skills. The current health care system limits the amount of client time spent directly with the nursing care provider. Nursing educators are challenged with developing ways to be with clients in the shorter amounts of time and still be empathic. The science of nursing is recognized in this study as an important part of nursing. Developing mechanical skills though is a small part of nursing. The completeness comes in joining the science with the art. As important as developing mechanical skills, is an emphasis on developing listening skills, an authentic presence, and appropriate touch. Nurses must learn early in their careers the value of responding to clients in ways that are meaningful to that client.

Findings of this study support the implications for administration in the development of an empathic friendly environment. Nursing administrators could model for all nurses caring and supportive behaviors. Administration is responsible for decisions that directly influence the patient care centers. These decisions affect the environment of both the client and nurse. The current economic system diminishes the time available to spend directly with clients. This study supports the value to the clients of time spent with the nurse. Administration must continue to develop plans to decrease 
the amount of time nurses spend occupied with non-nursing tasks. The decisions may be as direct as nursing care delivery models, client : nurse ratio and nursing development support. This study confirms that continuity of care by providers familiar with clients facilitated empathic interactions.

Adequate support of staff that serves to facilitate self -growth and development of self-awareness is essential. The idea of a debriefing time to allow nurses to express their thoughts and feelings about client interactions evolved from the investigator's experience of the subjects lingering to continue talking. The sense of satisfaction that was expressed about participating in this study suggests that nurses could benefit from debriefing sessions. This could be a scheduled period of time for nurses to share and could be led by rotating team member facilitators or facilitated by a psychiatric nurse liaison. These conversational debriefing sessions could lend themselves to the creation of an environment that assists in development of empathic processes as well as mutual support.

The implications for nursing research are that additional research is necessary to gain an increased understanding of empathy. Based upon further findings and the implications suggested for the clinical educational and administrative domains of nursing tools can be developed to measure and assess empathy.

\section{Limitations of the Study}


The study was limited by under representation of male nurse subjects. Two nominated male nurses were hesitant to participate in the study initially. A number of male clients were also reluctant to participate when approached. The research sample size was constrained by time limits for data collection prior to deadlines. Two male nominated nurses agreed to participate after the deadline had passed. Additional time perhaps would have allowed for their inclusion in the study.

if clients were able to fully participate secondary to fatigue and anxiety about their hospitalization.

The structured interview questions limited this research and prevents the work from being a phenomenological study. Due to the fact that this is not a phenomenological study, the method of analysis is a poor match. The Colaizzi method is indicated for true phenomenological studies. Content analysis would be an appropriate method for data analysis. There are suppositions built into the questions, especially Question \#2 and \#4 on the nurse and client interview. The phenomenological method of research aims to approach the research from a stance of unknowing. Care is taken to bracket out presuppositions. A review of literature is not done before the data collection. Questions are asked that do not have presuppositions built in. The questions in this study that are couched to yield a "yes" "no" response could be eliminated and replaced with one open question. In this study there was no prompting and most subjects did not digress from the specific questions asked. Some participants did feel free to introduce personal thoughts and observations to add a further perspective and 
depth to the interview. Perhaps a question suggesting that the subject recall and discuss past experiences of empathic interactions would have yielded a fuller exploration of the topic and an added richness to the protocols. The quality of the data could have been enriched by guiding the subjects to tell more about what they mean, through examples or stories.

An additional weakness is that the complete protocol is not taped and transcribed from beginning the end. In this study the tape recorder was turned on once the interviewer was ready to start asking the prescribed question and turned off once the questions were answered. It would have been more appropriate to start tape recording at the very beginning of the contact with the subject and end once the contact was terminated. This practice would have captured the debriefing conversations.

Excluding nurses that were not nominated by their nurse managers may have prevented the viewpoint that they hold regarding empathic interactions. The same holds true for clients that were not nominated by their nurse participants. Another limitation was that one nurse became ill the day after the interview and so the researcher was not able to interview a matching pair client. Perhaps the fact that the investigator was a nurse restricted the clients from full disclosure, especially if they had had as especially negative experience with a nurse.

\section{Credibility of Results}

The issue of validity and reliability is associated with quantitative research. It is not appropriate in qualitative research. The issue of credibility is more relevant. 
Credibility is an equivalent to internal validity of quantitative research. There is a step in Colaizzi's analysis that checks credibility. The final step is a return to the participants to ask about the findings. This was done with five of the nurse participants and one of the client participants. They were asked if the findings compared with their experience. There was agreement from all or the subjects revisited. There was pursuing discussion that did not reveal any contradictions.

Recommendations for Further Study

There are many themes that surfaced in this study that merit further investigation. Questions remain about the nature of empathy, if it can be taught, if it can be accurately measured, if it can be observed. A fertile area for further research is that of the relationship between the ability to engage in empathic interactions and lack of "burnout" and increased satisfaction. Much remains to be known about the facilitation of the teaching of empathy.

\section{$\underline{\text { Summary }}$}

Qualitative research supports and validates the practice of holistic nursing through attempts to more fully understand human nature. This study has provided a greater understanding of empathic interactions as perceived by these subjects. It is now understood that performing nursing in an empathic manner is important to both clients and nurses. It is an essential value, in an economic climate that is influenced by satisfaction it is important not to ignore this information. Satisfaction plays a role in the quality of persons lives. 


\section{References}

Alverson, E. (1987). The pre-operative interview: its effects on nurses' empathy.

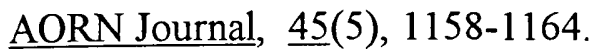

ANA Cabinet on Nursing Research, (1985), Directions for nursing research:

Toward the 21st century. Kansas City, MO:ANA Publications.

Aspy, D.N. (1975). Empathy: Let's get the hell on with it. Counseling Psychologist, $\underline{5}(2), 10-14$.

Barrett-Lennard, G.T. (1962). Dimensions of therapist response as casual factors in therapeutic change. Psychological Monographs, 76(43), 562.

Bartol, G. (1984). Nursing: An art and a science. Nursing Outlook, 32(1), 63-

5.

Beck, C.T. (1994). Phenomenology: its use in nursing research. International

Journal Nursing Studies, $\underline{31}$ (6),499-510.

Bradley, J., \& Edinberg, M. (1982). Communication in the nursing context. New York: Appleton-Century-Croft.

Brown, N.W., \& Hunter A. (1987). Empathy scores of nurses, psychiatrists, and hospital administrators on the California Psychological Inventory. Psychological $\underline{\text { Reports, }}$ 60, 295-300.

Brunt, J.H. (1985). An exploration of the relationship between nurses' empathy and technology. Nursing Administration Quarterly, 9(4), 69-78.

Buber, M., (1937) . I and Thou. (R.G. Smith, trans.) Edinburgh: T \& T Clark 
Buber, M., (1955). Between man and man. Boston: Beacon Press.

Burgess, A. (1990). Psychiatric nursing in the hospital and the community.

Norwalk, CT: Appleton \& Lange.

Burns, N. \& Grove, S.K. (1987). The practice of nursing research: conduct, critique and utilization. Philadelphia: W.B. Saunders.

Carkhuff, R.R. (1969). Helping and human relationships: A primer for lay and professional helpers (Vols. 1-2). New York: Holt, Reinhart \& Winston.

Chapman, C. (1983). The paradox of nursing. Journal of Advanced Nursing $\underline{8}$, 269-272.

Chapman,C. (1990). Empathy. Journal of Advanced Nursing, 15, 1173.

Clark, K.B. (1980). Empathy: A neglected topic in psychological research.

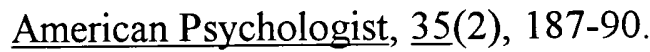

Colaizzi, P. (1978). Psychological research as the phenomenologist views it. In R.Valle \& M. King (Eds.) Existential-phenomenological alternatives for psychology . (pp48-71). New York:Oxford University Press.

Comptom, M. (1987). A Rogerian View of Drug Abuse: Implications for Nursing. Nursing Science, 98-105.

Daeffler, R.J. (1975). Patients' perception of care under team and primary nursing. Journal of Nursing Administration, $\underline{5}(3), 20-26$.

Davis, C.M. (1989). Patient Practitioner Interaction, Thorofare: Slack Inc. 
Deutsch, F. \& Mandle, A.R. (1975). Empathy: historical and current conceptualizations, measurement and cognitive theoretical perspective. Human Development. 18, 267-287.

Duff, R.S, Hollingshead, A. (1968). Sickness and Society New York: Harper and Row.

Forsyth, G.L. (1979). Exploration of empathy in nurse-client interaction. Advances in Nursing Science, 1 (2), 53-60.

Forsyth, G. (1980). Analysis of the concept of empathy. Advanced Nursing Science, $\underline{2}, 33-42$.

Forsyth, G. (1989). Can Caring Behavior's be Taught? Nursing Outlook.

Gagan, J.M. (1983). Methodological notes on empathy. Advances in Nursing Science, $\underline{5}(2), 65-72$.

Gazda, G.M., Childers, W.C., \& Brooks, D.K. (1987) Foundations of Counseling and Human service, New York :McGraw Hill.

Geach, B. \& White, J.C. (1974). Empathic resonance: a countertransference phenomenon. American Journal of Nursing, 74, 11282-1285

Gladstein, G.A. (1984). Understanding empathy: Integrating counseling, developmental and social psychology perspectives. Journal of Counseling Psychology, $\underline{30}, 467-482$.

Goldstein \& Michaels (1985). Empathy:Development, training, aand consequences. Hillsdale, NJ:Erlbaum 
Gould, D. (1990). Empathy: A review of the literature with suggestions for an alternative research strategy. Journal of Advanced Nursing, 15, 1167-1174.

Henderson, V. (1964). The nature of nursing. American Journal of Nursing, $\underline{64}(8), 62-68$

Hills, M. \& Knowles, D. (1983). Nurses' levels of empathy and respect in simulated interactions with patients. International Journal of Nursing Studies, 20, 83-87.

Hogan, R. (1969). Development of an empathy scale. Journal of Consulting and Clinical Psychology, $\underline{33}$ (3), 307-316.

Holden, R.J. (1990). Empathy: The art of emotional knowing in holistic nursing care. Holistic Nursing Practice, 5 , 70-79.

Holliday, J. (1961). The ideal characteristics of a professional nurse. Nursing Research, 10, 205-210.

Holm, K. (1989). Effects of personal pain experience on pain assessment. Image, $\underline{21}(2), 72-75$.

Holtzman, R. (1989). Patient advocate - a lesson in empathy. $\underline{\mathrm{RN}}, \underline{11}, 21-2$.

Hourard,

Jones, J. (1990). A question of empathy. Journal of Nursing Times, Jan., 43-5.

Kalisch, B.J. (1971). An experiment in the development of empathy in nursing students. Nursing Research, 20(3), 202-11.

Kalisch, B.J. (1973). What is empathy? American Journal of Nursing, $\underline{73}$, 154852. 
Kunst-Wilson, W., Carpenter, L., Poser, A., Venohr, I. \& Kushner, K. (1981).

Empathic perceptions of nursing students: Self reported and actual ability. Research in Nursing and Health, 4, 283-293.

LaMonica, E.L., Carew, D.K., Winde, A.E. (1976). Empathy training - a major thrust of a staff development program. Nursing Research, 25, 447-451.

LaMonica, E.L. \& Karshmer, J.F. (1978). Empathy: Educating nurses in professional practice. Journal of Nursing Education, 17(2), 3-11.

LaMonica, E.L. (1979). Empathy in nursing practice. Issues in Mental Health Nursing, $\underline{2}, 2-13$.

LaMonica, E.L. (1981). Construct validity of an empathy instrument. in Nursing and Health, 4 , 389-400.

LaMonica, E.L., Wolf, R.M., Madea, A.R. \& Oberst, M.T. (1987). Empathy and nursing care outcomes. Scholarly Inquiry for Nursing Practice, 1(3), 197-212.

Layton, J.M.(1979). The use of modeling to teach empathy to nursing students. Research in Nursing and Health, 2, 163-176.

Lipps, T. (1903). Empathy, inner imitation, and sense--Feelings. In M.M. Rader (Ed.) (1935), A modern book of esthetics: An anthology. (pp287-304). New York: Henry Holt.

MacDonald, M. (1977). How do men and women students rate in empathy? American Journal of Nursing, 77. 998. 
Mansfield, E. (1973) Empathy: Concept and identified psychiatric nursing behavior. Nursing Research, 22. 525-529.

Morath, J. (1989). Empathy training - development of sensitivity and caring in hospitals. Nursing Management, $\underline{30}, 60-2$.

Morse, J.M., Bottorff, J., Anderson, G., O’Brien, B., \& Solberg, S. (1992A). Beyond empathy: expanding expressions of caring. Journal of Advanced Nursing, 17, 809-821.

Morse, J.M., Anderson, G., Bottorff, J., Yonge, O., O’Brien, B., Solberg, S.M., \& McIlveen, K.H. (1992B). Exploring empathy: A conceptual fit for nursing practice? Image, 24, 4 273-280

Movriah, P. (1989). Nursing and caring. Journal Advanced Nursing, (5), 421-6. Mynatt, S. (1985). Empathy in faculty and students in different types of nursing preparation programs. Western Journal of Nursing Research, 7. 333-348.

Nightingale, F., (1946). Notes on Nursing - What it is and what it is not. New York: Appleton Century.

Norris, C., (1973). Delusions that trap nurses. Nursing Outlook, 21,19.

Peitchinis, J.A. (1972). Therapeutic effectiveness of counseling by nursing personnel. Nursing Research, 21 (2), 138-148.

Peplau, H.E. (1952). Interpersonal relationships in nursing New York: G.P. Putnam. 
Pluckman, M.L. (1978). Human Communication: The matrix of nursing. New York: McGraw Hill.

Podrasky, D.L. \& Sexton, D.L. (1988). Nurses' reactions to difficult patients. Journal of Nursing Scholarship, 20, (1), 16-20.

Ray, M. (personal conversation January 1996)

Rogers, C.R. (1957). The necessary and sufficient conditions of therapeutic personality change. Journal of Consulting Psychology, 21, 95-103

Rogers, C.R. (1958). The characteristics of a helping relationship. Personnel and Guidance Journal, $\underline{37}$, 6-16.

Rogers, C.R. (1961). On becoming a Person. Boston: Houghton Miffin.

Rogers, C.R. (1975). Empathic: An unappreciated way of being. The

Counseling Psychologist. $\underline{5}(2), 2-10$

Rogers, M.E. (1970). An introduction to the theoretical basis of nursing. Philadelphia: F.A. Davis

Rogers, M.E. (1987). Rogers' science of unitary human beings. In R.R. Parse, Nursing Science, major paradigms, theories, and critiques. (pp. 139-146). New York: W.B. Saunders.

Rogers, M.E. (1990). Nursing: Science of Unitary, irreducible, human beings: Update 1990. In E.A.M. Baarrett (Ed.) Visions of Roger's science-based nursing (pp. 511) New York: National League for Nursing. 
Sanchez, R. (1989). Empathy, diversity and telepathy in mother-daughter dyads: An empirical investigation utilizing Rogers' conceptual framework. Scholarly Inquiry for Nursing Practice, 3, 29, 45.

Sandelowski, M. (1986). The problem of rigor in qualitative research. Advances in Nursing Science, $\underline{8}(3), 27-37$.

Sparling, S.L. \& Jones, S.L. (1977). Setting: a contextual variable associated with empathy. Journal of Psychiatric and Mental Health Services, 15, 9-12.

Stein, E.S. (1970). On the problem of empathy (W. Stein, Trans.). The Hague: Martinus Nihjoff (original work published 1917).

Stetler, C.B. (1977). Relationship of perceived empathy to nurse's communication. Nursing Research, 26(6), 432-437.

Stockwell, F. (1972). The unpopular patient, Royal College of Nursing, London.

Southerland, J. (1993). The nature and evolution of phenomenological empathy in nursing: A Historical treatment. Archives in Psychiatric Nursing Vol. II, 6, 369-376.

Tilden, V.P., Nelson, C.A. \& May, B.A. (1990). Use of qualitative methods to enhance content validity. Nursing Research $39,3.172-175$.

Travelbee, J. (1964). What do we mean by rapport? American Journal of Nursing, 63, 70-72,

Triplett, J.L. (1969). Empathy is ... Nursing Clinics of North America, 4(4), 67381. 
Truax, C.B. (1961). A scale for the measurement of accurate empathy.

Psychiatric Institute Bulletin. University of Wisconsin.

van Manen, M. (1984) Practicing phenomenological writing. Phenomenol.

Pedag. 2, 36-69.

Wheeler, K. (1988). A nursing science approach to understanding empathy.

Archives of Psychiatric Nursing, 2 , 95-102.

Zderad, L.T. (1969). Empathic nursing: Realization of a human capacity. Nursing

Clinics of North America, 4 (4), 655-662. 
Appendix A(1) Semistructured Interview

Nurse

1. What do you think empathy is?

2. Would you agree that empathy can be the ability to perceive the meanings and feelings of another person and to communicate that understanding to the other?

3. How does a person convey empathy?

4. Have you ever felt a sense of energy being exchanged in a process of empathy?

5. How can you tell that you are conveying empathy?

6. How does it feel for you when you are feeling empathic toward a patient?

7. How is empathy a part of nursing? 
Appendix A (2) Semistructured Interview

Client

1. What do you think empathy is?

2. Would you agree that empathy can be the ability to perceive the meanings and feelings of another person and to communicate that understanding to the other?

3. How might a nurse convey empathy to a patient.

4. Have you ever felt a sense of energy being exchanged in a process of empathy?

5. What do you think the nurse would do to let you know that she/he was feeling empathic toward you?

6. What do you think the nurse would say if she/ he was feeling empathic toward you?

7. What do you think a nurse would feel if she/he was feeling empathic toward you?

8. How would it feel to you if the nurse was feeling empathic?

9. Is it important to you for a nurse to be empathetic? Why? 
Appendix B (1) Invitation to participate.

Dear (Nurse)

My name is Patricia Calhoun, and I am a student at Florida International University School of Nursing. I am working on my thesis. My topic is empathy. I am exploring the perceptions of nurses and clients related to empathic processes. You have been identified as a possible participant.

I would like to interview you and ask you to answer a series of questions. The purpose of the interview is to discuss your thoughts and feelings on empathy. The interview will last for approximately one hour and will be scheduled at a time of your choice.

The study has been approved by Jackson Memorial Hospital at the University of Miami Medical Center and Florida International University's Institutional Review Board. There is no financial reimbursement for your participation. Your participation is entirely voluntary. You may withdraw from this study at any time. Your participation or refusal to will not affect your employment at all.

Benefits to you will be the opportunity to share your philosophy of nursing and your insights in nurse empathy. Be assured that anonymity and confidentiality will be maintained through a series of protective steps.

A summary of the study will be available for you upon completion.

I look forward to meeting with you and getting to know your thoughts on nurse /client perceptions of empathy. If you have any questions concerning this study or your 
participation in it, please do not hesitate to call and talk with me, I can be reached at 431-6063 late evenings and digital beeper 843-8749 during daytime hours. Thank you for your participation.

Sincerely,

Patricia Calhoun 
Appendix B (2) Invitation to participate.

Dear (Client)

My name is Patricia Calhoun, and I am a student at Florida International University School of Nursing. I am working on my thesis. My topic is empathy. I am exploring the perceptions of nurses and clients related to empathic interactions. You have been identified as a possible participant.

I would like to interview you and ask you to answer a series of questions. The purpose of the interview is to discuss your thoughts and feelings on empathy. The interview will last for approximately one hour and will be scheduled at a time of your choice.

The study has been approved by the Jackson Memorial Hospital at the University of Miami Medical Center and Florida International University's Institutional Review Board. There is no financial reimbursement for your participation. Your participation is entirely voluntary. Refusal to participate will not affect the care you receive at this facility. You may withdraw from this study at any time

Benefits to you will be the opportunity to share your thoughts on empathy. You can be assured that anonymity and confidentiality will be maintained through a series of steps.

A summary of the study will be available for you upon completion.

I look forward to meeting with you and getting to know your thoughts on empathy. If you have any questions concerning this study or your participation in it, 
please do not hesitate to call and talk with me, I can be reached at 431-6063 late evenings and digital beeper 843-8749 during daytime hours. Thank you for your participation.

Sincerely,

Patricia Calhoun 


\section{INFORMED CONSENT FORM}

SUBJECT'S NAME:

TITLE OF RESEARCH PROTOCOL: Empathy

PRINCIPLE INVESTIGATOR Patricia Calhoun

RESEARCH PROTOCOL \#

1. PURPOSE OF THE STUDY

The purpose of this study is to explore the perceptions of nurses and clients related to empathic interactions.

2. PROCEDURE

The procedure for exploring the perceptions will consist of the participants participating in an interview. The interview will guide the participants to discuss their thoughts and experiences of empathic interactions.

3. RISKS AND DISCOMFORT

It is not expected that the you will be subjected to any risks or discomfort greater than those faced in daily life.

\section{BENEFITS}

There are no direct, measurable benefits to you for participating in this study.

You may benefit from knowing that you have contributed toward an increased understanding of the perceptions of empathy. 


\section{ALTERNATIVE PROCEDURE}

You may choose at any time not to participate in this study. Your refusal will in no way affect your care or relationship with your health care provider.

\section{COST/PAYMENT}

There is no cost to you for your participation. You will not be paid for participating in this study.

\section{CONFIDENTIALITY}

Your identity will remain anonymous and your responses confidential. Your name will not appear anywhere on the report of the research. Your interview notes will be coded so that your name does not appear on the records. The code key will be kept in a locked file and then destroyed once the study is completed. Any quotes from the interview will be presented with other quotes in an unidentifiable fashion. Any names used during the interview will be changed.

I have fully explained to the subject, the nature and purpose of the procedures described above and such risks. I have asked the subject if any questions have arisen regarding the procedure and have answered these questions to the best of my ability. 
I have been fully informed about the above procedure, with it's possible benefits, risks, and consequences. I recognize that I am free to ask any questions. I understand that participation in this study is voluntary and I am free to withdraw from this study at any time without affecting my care or relationship with my health provider.

I will receive a copy of this consent form. Jackson Memorial Hospital maintains an Institutional Assurance of Compliance, a document which explains how the hospital provides for protection of human subjects, a copy of which is available upon request. I agree to become a subject for this investigation

Date Subject's Signature

I have witnessed the explanations made by the Investigator and heard the responses to questions. I have no conflicting interest in the activity proposed.

Date

Witness

For any questions regarding the right of a research subject, Please contact Ann Lynn

Denker Director of Nursing Research at telephone number 585-6483 
Appendix D (1)

\section{DEMOGRAPHIC INFORMATION}

NURSE

AGE

GENDER

YEARS OF NURSING EXPERIENCE

AREA OF SPECIALIZATION

PREVIOUS EXPERIENCE AS A HOSPITALIZED PATIENT

\section{CLIENT}

AGE

GENDER

PREVIOUS EXPERIENCE AS A HOSPITALIZATION

LEVEL OF EDUCATION 


\section{Appendix E Transcriptions of Interviews}

\section{Transcription of interview - Nurse N01}

1. What do you think empathy is?

For me empathy is a moment when you can really connect with somebody and they feel that you are really there for them.

2. Would you agree that empathy can be the ability to perceive the meanings and feelings of another person and to communicate that understanding to the other?

I think that is a big part of empathy. Yes, definitely.

\section{How does a person convey empathy?}

I think being totally there, just strictly focusing on what they are saying, what they are feeling, not letting outside distractions take even a minute of your time away from them. Just completely being there, listening to what they are saying, and letting them know that you are really hearing what they are trying to get across to you.

4 Have you ever felt a sense of energy being exchanged in a process of empathy?

To be honest, going back to that episode, at the moment I can't say right at the moment at that split second, that I felt that, but I did afterward. I felt that it left me with something, hopefully it got him through what he was going through at the time. It definitely affected me.

\section{How can you tell that you are conveying empathy?}

You know I've never really thought about it at the time, I guess I have to go back to feeling as though I am connecting with somebody. I don't consciously think "I'm being empathetic at this moment" I just rely on the feedback that I am getting from the other person. And then I just go with that, I can't say as though it is a conscious effort on my part when I am actually doing it.

\section{How does it feel for you when you are feeling empathic toward a patient?}

For me it's a very real moment. Once again it's just that being present, just a feeling that "I want to help you. I'm here for you. What can I do, I'm here what can I do ? I want to be part of getting you through this. It's not verbal they don't have to tell you what to do. It might be just listening, just listening alone is a big part of it. Sometimes helping them, when you hear what they are saying, helping them to sort it out. Even though they may not tell you. They may not say "Help me to sort this out, in your mind when you listen to them you kind of figure it out in your own mind, you give them your opinion, Again, it is just really being there for them. Just listening to them.

Well, I am thinking of an experience that I had just recently, with a young man , twenty five years old, who was having, at the time we didn't know it, but he was having a drug reaction. It wasn't exactly seizures, but he was aware, he was fully aware of what was happening to him, but he couldn't communicate to me at that moment all that he was experiencing, I felt as though, I had to be there for him just so he knew that 
someone was going through it with him. Just so he knew that he was not alone. I felt the need to touch him, to be there for him, even though I know that he couldn't communicate right at that moment that he appreciated what I was doing.

7. How is empathy a part of nursing?

It is difficult for me, I never really thought about empathy, that you try to define it or. It's just a split second, of course it's never a split second, sometimes it is much more than that, minutes, an hour, however, but at the time it's just that minute when you connect and you just want to be there. It's someplace you want to be. It's someplace you place yourself to be. I still think it is nonconsciously placing yourself there. It's not a conscious effort, no matter how long or short it is. For me it is never conscious. It's almost magical. Looking back on it is a very magical moment. To think that we (nurses) have all had this experience, it's really pretty wonderful. Now that I am thinking about it, it is on a different plane. You are taken to a different plane.

I think empathy is probably the biggest part of nursing. Unfortunately, you are not given alot of time. How can I put this? I think empathy is the biggest part of nursing, it's probably good it's not a conscious effort or it wouldn't get done half as much as it should get done. Empathy is every part of nursing. As soon as you meet a person, when you are trying to, it's just every part of nursing, everything you do. The first words you say to a person, if you expect them to be receptive to any teaching that you might want to do, or to take part in their own care, they have to know that you are really, you are a big motivator for them and to me it (empathy) is the key to everything you do with that person. It's how they look at you, and how they are going to respond to whatever you may do for them. 
1 . What do you think empathy is?

To me empathy is like trying to put yourself in the place of the other person, to try to figure out how they are feeling.

2. Would you agree that empathy can be the ability to perceive the meanings and feelings of another person and to communicate that understanding to the other?

Yes, I agree with that.

\section{How does a person convey empathy?}

I think just by the way, what they say to the person, the body language, the look, if they are saying things that make it obvious to the other person that the person does see how they are feeling, can see things from their perspective, that conveys empathy.

4 Have you ever felt a sense of energy being exchanged in a process of empathy?

Yes, I would say that I agree. You can feel a certain bond with a person. If you could translate that bond to being energy, I could agree. That certain bond can also energize you. The bond feels like kinda you are touching base with somebody and you are just together with somebody. It is more than just physical.

\section{How can you tell that you are conveying empathy?}

From the reaction of the person, if they also seem like they are receiving this or they are sort of on the same wave length I think that let's you know as opposed to if the person is not really there, like if they are way off on another thing and is not relating at all, maybe it is not being conveyed.

6. How does it feel for you when you are feeling empathic toward a patient?

I think it feels good, I mean it feels right when I am feeling empathic toward a patient. I

7. How is empathy a part of nursing?

Well, I think it is part of nursing, part of meeting a person's needs it is important to see things from their view so that you can facilitate things for them or whatever. If you can see and try to picture how they are seeing life or things, then you can help them go towards these things in a way that is meaningful to that person. Rather than just following a procedure, or whatever in a way that may not be meaningful to that person. I think it is part of nursing as far as anything that you can do to see that person's view so you can figure out ways of doing things that would matter to that person and help them in whatever need that they have. 
1. What do you think empathy is?

It is a state of grace. A moment in a connection with a person when the rest of the world stops. You only are aware of what is happening at that moment with the person you are with. Sometimes you can really feel what the other person must be feeling. Othertimes, you don't know what they are feeling but you do feel like you are right with them, every step of the way at that moment. It is hard to explain. You know, it is like it is more of a sensation, a feeling. Not so much a thought.

2. Would you agree that empathy can be the ability to perceive the meanings and feelings of another person and to communicate that understanding to the other?

Yes, I would agree. It is not what I said, but I think it is what empathy is. Only thing is, you don't always perceive the meaning. Sometimes it is just the feeling. It depends, if you just met the person you might not know the meaning yet. If you did know them for a while, you probably know something about the meaning.

\section{How does a person convey empathy?}

I don't think that you try to convey empathy. It just happens. I guess that is why I say it is a state of grace. Empathy can be expressed in many different ways. OK, it could be a look in the eyes, a knowing nod, just listening and being with a person. Or, you might not say or do anything. It's like I said, it is a feeling. Or, it could be conveyed in a long tight hug, or holding on to a person's shoulders and looking them in the eyes. It is usually conveyed in a quiet manner. It is not something that other people know about. It is just between you and the person. It may start out with conversation getting to know the person and how the person is and then as they share it may become quiet as you connect. That's how it is for me.

4 Have you ever felt a sense of energy being exchanged in a process of empathy?

Yes. And it is very powerful. I think that is where you feel the connection sometimes. You look at the person and you can really feel the connection. Now that I think about it, it must be the energy. Sometimes you don't feel the energy, especially if you are doing other things at the same time. You know how sometimes you are taking care of a person, and you have alot of things to do, you try to do more than one thing at a time. You talk to the person at the same time that you are doing the other work. You listen, but you are kinda distracted by what else you are doing. Finally, when I stop doing what else I am doing, then I may feel the energy as I feel more connected and attentive of the person and not the tasks.

\section{How can you tell that you are conveying empathy?}

I don't think I can always tell. Sometimes I am surprised when a patient remarks that they feel as though I am very understanding and caring. When I do sense that I am conveying empathy, I would describe it as a very full feeling. I am fully aware of I'll use the word "connection" again. I feel the connection between us. It is a very full feeling 
when I pay attention to it. It is like using all my senses. I am connected. I am not distracted. We are right there at that moment together. Joined in the moment. At times I feel a tenderness from me. A, how can I say it, a focus just on that person. Usually there is alot of eye contact. There is a slowness of motion. Again, I say, not much talking. Really listening. Even to the silence between us. It is a very special feeling.

6. How does it feel for you when you are feeling empathic toward a patient?

Like I said, it just feels right. It is a fulfilling feeling. A fullness that is light. There is a sense of satisfaction, but that is not the primary thing. It, the feeling is sustaining. I really think it is a state of grace. And it lasts for more than the moment. It wakes you up to remind you that what you do is meaningful. It is something to strive for.

7. How is empathy a part of nursing?

I guess I already answered that in the last one. Empathy is an integral part of real nursing. It lets you know that you are really connected. You have made a difference in the patients life, and your life. There is meaning for both of you. That's what nursing is all about, isn't it? We try to help people during the times when they are going through health problems. Our goal is to help them adjust to the changes in their life. I guess what I should say is that it sure is more satisfying for both the nurse and patient when empathy is part of the encounter. 
Transcription of Interview - Nurse N04

1 . What do you think empathy is?

Meeting the person wherever they are. You know how it is here. We have alot of patients. Each one is different. All different cultures. All different medical problems. Some are unaware of what is wrong with them and some know more than I know about them. Empathy means that you put that all aside and just meet them where they are. Then you go from there. You try to feel what they must be feeling. You try to get their perspective.

2. Would you agree that empathy can be the ability to perceive the meanings and feelings of another person and to communicate that understanding to the other?

Yes. Exactly.

3. How does a person convey empathy?

All kinds of ways. It is an individual way. Everyone does it different. You start out, like I said, by meeting them where they are. That's the start. Then depending on where they are and what they need, you go from there. Most of all it takes time, you listen first, and if they don't talk, you watch them. You think about what is going on. You put the pieces together and then try to feel what they must be feeling. You let them know what you know about what they are going through. You talk to them. You touch them if that's what they need.

4 Have you ever felt a sense of energy being exchanged in a process of empathy?

I never thought about it as energy but I guess that's what it is. Sometimes it is so powerful. It is different than sympathy. That is a sad thing. This is different. You know when it happens. It is a special connection. You can feel it.

\section{How can you tell that you are conveying empathy?}

It is a back and forth feeling. You feel it and you know that the other person is feeling it. They tell you how they appreciate it or they just look at you with a sweetness. Sounds funny when I say it that way, but that is how it feels to me.

6. How does it feel for you when you are feeling empathic toward a patient?

Very rewarding. It is what nursing is all about. You are helping that person and you both know it.

7. How is empathy a part of nursing?

Like I said in the beginning, it is what we try to do. We try to meet them wherever they are and make a connection. 


\section{Transcription of interview -Client}

1. What do you think empathy is?

I think it is when someone really cares about someone else. They try to find out how they are. They don't just care about how your blood is. They care about how you feel. They try to see if you are scared. They try to find out what you need.

2. Would you agree that empathy can be the ability to perceive the meanings and feelings of another person and to communicate that understanding to another?

I guess.

3. How might a nurse convey empathy to a patient?

She could ask questions about your family. She could remember you for the next time you come back. She could stay in your room for a while. She could come and check on you when she can. She could listen to you.

4. Have you ever felt a sense of energy being exchanged in a process of empathy?

I don't know about that. First time I came here, I was real scared. I can't hardly remember it now. I just found out I had cancer. I didn't know anything about it. People told me things but I wouldn't remember it. I was real tired all the time. Then with the medicine I got sicker. Then I was real scared and I stayed in bed all the time. One nurse always came in to see me. She would talk to me. She didn't make me talk though. She told me she knew that I was real tired. She told me I would get strong though. She was right. She is my favorite nurse now. Now, I'm stronger so I talk to her more when she comes in. She does her writing right here in my room. I like that.

5. What do you think the nurse would do to let you know that she/he was feeling empathic toward you?

She would come to your room. She would see how you were. She would know if you just wanted to be quiet. She wouldn't ask you alot of questions.

6. What do you think the nurse would say if she/he was feeling empathic toward you?

I'm sorry you don't feel good today. You will get stronger though. Your blood will get built up.

7. What do you think a nurse would feel if she/he was feeling empathic toward you?

She would know that she is doing a good job.

8. How would it feel to you if the nurse was feeling empathic?

It would feel like someone cared. I wouldn't feel so alone and scared.

9. Is it important to you for a nurse to be empathic? Why? 
It is good when a nurse does that. Then you don't feel so scared. You can rest so then you find out what happens and you get stronger. 
Transcription of Interview -Client CL02

1. What do you think empathy is?

Concern for one's being.

2. Would you agree that empathy can be the ability to perceive the meanings and feelings of another person and to communicate that understanding to another?

Yes.

3. How might a nurse convey empathy to a patient?

By listening well to the concerns. And conveying to the person ways to help to overcome the shortcomings.

4. Have you ever felt a sense of energy being exchanged in a process of empathy? No.

5. What do you think the nurse would do to let you know that she/he was feeling empathic toward you?

To exhibit deep concern for your concern.

6. What do you think the nurse would say if she/he was feeling empathic toward you?

"I understand," "I see," agreeing with the person.

7. What do you think a nurse would feel if she/he was feeling empathic toward you?

Depends on her makeup. She should feel concern, and a wanting to help the person.

8. How would it feel to you if the nurse was feeling empathic?

As a patient? It would be beneficial to my well-being.

9. Is it important to you for a nurse to be empathic? Why?

Absolutely. To exhibit concern for my concern is important. 
1. What do you think empathy is?

I think empathy is a feeling for another person. Having feeling for them.

2. Would you agree that empathy can be the ability to perceive the meanings and feelings of another person and to communicate that understanding to another?

Right, I do.

3. How might a nurse convey empathy to a patient?

By touch, you know by holding your hand. Or by words, just showing concern.

4. Have you ever felt a sense of energy being exchanged in a process of empathy?

I would say yes.

5. What do you think the nurse would do to let you know that she/he was feeling empathic toward you?

Touch you, just hold your hand as I said before. By words. Just being there.

6. What do you think the nurse would say if she/he was feeling empathic toward you?

I understand how you are feeling, or some sympathetic gesture. That's about it.

7. What do you think a nurse would feel if she/he was feeling empathic toward you?

I think she would probably feel a little sad, maybe for the person. An understanding of what they are going through.

8. How would it feel to you if the nurse was feeling empathic?

Oh, I think that would be a helpful feeling. I think it would make you feel comforting to know that someone was feeling that way.

9. Is it important to you for a nurse to be empathic? Why?

Oh, yes. Definitely. I think it shows that they care. That you are not alone.

That someone else cares what's happening to you. That there is not a coldness. There is a warmth from another person. To feel for you. 
1. What do you think empathy is?

How you feel about each other.

2. Would you agree that empathy can be the ability to perceive the meanings and feelings of another person and to communicate that understanding to another?

I guess.

3. How might a nurse convey empathy to a patient?

She could hold your hand if you are nervous. She could care about you and tell you not to worry. She could ask you how you feel. Cause she knows you know about your own body. You know how you normally feel. She could show you that she knows you know about your body.

4. Have you ever felt a sense of energy being exchanged in a process of empathy?

I don't know what that is . (After explanation) I don't think so. It means alot to me when nurses put their arms around me. Is that what you mean?

5. What do you think the nurse would do to let you know that she/he was feeling empathic toward you?

Pay attention to you. Look at you when you are talking. Try to understand you. Help you to tell the doctor something. She could just believe what you say and let you know that she believes you.

6. What do you think the nurse would say if she/he was feeling empathic toward you?

I care about you. She could tell you something she remembers about you from the last time you were in the hospital. I remember one time I came back in for more chemo and this one nurse was happy to see me. She asked me about my dog. I had forgotten I had told her. It was funny, when she said that, I knew that she remembered me and she cared about me. They have alot of things to remember, imagine that she remembered my dog. That was real nice.

7. What do you think a nurse would feel if she/he was feeling empathic toward you?

It must feel bad sometimes, because everyone here has cancer. If they get involved with everyone it must be real hard. I asked one nurse about that but she told me they learn about that, they know how to take care of themselves. But still it must be hard.

8. How would it feel to you if the nurse was feeling empathic?

It feels good. Like I said it's nice when they remember you. It makes you feel important. You almost feel like you are part of this floors' family. I don't know if 
everyone feels that way, but sometimes I do. Like when I have a roommate, and the nurse comes in and we joke and laugh.

9. Is it important to you for a nurse to be empathic? Why?

Yes, cause then you feel more comfortable, you know that they care. Like you belong. While you are in the hospital you know that they (nurses) are going to care about you. They will make sure you are all right. They will notice if something is wrong. 
1. What do you think empathy is?

It's going beyond knowing the facts about a patient. Like what is wrong with them and what the plan of care is. It is really knowing what the patient is feeling. What all this means to the patient. How being in the hospital is affecting them. Empathy is understanding how the patient feels. You try to put yourself in their place and see how they feel.

2. Would you agree that empathy can be the ability to perceive the meanings and feelings of another person and to communicate that understanding to the other?

Yes. It has to work both ways. You can't just think you know how the patient feels. They have to be involved and know how you feel about them. That you care. That you have an interest in them.

\section{How does a person convey empathy?}

There are many ways to convey empathy. It begins with really listening, asking the right questions, sometimes you just repeat back what you are hearing from them. You want to make sure you understand what the patient is feeling or saying.

4 Have you ever felt a sense of energy being exchanged in a process of empathy?

I guess it is energy that you feel. It is a strong bond that you are aware of. Something happens. You feel the connection of putting yourself in the patient's place. You really feel what they must be feeling. It's like you are really in their place. Knowing what it is like for the patient. For me it doesn't happen all the time. But when you do feel it, you know it. I never thought of calling it energy.... but it must be. It is a strong bond. You can feel it.

\section{How can you tell that you are conveying empathy?}

It's that bond that you feel. You know, it's hard to explain. It is a feeling. It's like you know what the patient is going to say even before they say it. You know what they are going to say. The patient knows that you know too. You know that you are conveying empathy when you feel that bond.... that connection when you know what they are feeling.

6. How does it feel for you when you are feeling empathic toward a patient?

Afterward, mostly it is a rewarding feeling. It makes what I do worthwhile. Never much thought about it but it does feel good when it happens. You work so hard trying to help patients, moving from one room to another, juggling everything that you have to do. Sometimes you don't stop for a minute, but then when you feel that bond it makes it all worthwhile. You aren't always aware of it at the moment though. 
7. How is empathy a part of nursing?

It's not always a part of nursing. What it is though is what we try to strive for. We try to be there for patients. Helping them to figure out what they are feeling, what this means for them, how the illness is affecting them. Sometimes that is the most you can do for them. Patients need help with this. Sometimes they need help thinking through what's wrong and what they need to do to get better. We can help with that. Sometimes they are too caught up in feeling scared. If we can really connect with them and they can feel the bond between us that's a big part of nursing. 
1. What do you think empathy is?

Empathy is the ability to perceive the other peoples feelings and to be able to communicate with the patient.

2. Would you agree that empathy can be the ability to perceive the meanings and feelings of another person and to communicate that understanding to the other? I do.

3. How does a person convey empathy?

For example I work also in an ENT clinic, sometimes we get the very seriously ill patient, and sometimes the doctors sort of a break the news, that a how real they are, even though they don't feel that way. At that time you can't console them. But if you just stand near the patient, hold their hand and I think though, that you are communicating your feelings and they will understand that you are sort of feeling for them and you are understanding. That is empathy. By holding the patients hand you can convey. The physical contact, little bit it conveys so much things.

4 Have you ever felt a sense of energy being exchanged in a process of empathy?

I think I do. I don't have to tell that patient and when I touch, with the touch I can convey. I am sure the patient feels the same thing. Yes it is a sense of energy.

5. How can you tell that you are conveying empathy?

This is really, you can't describe it in words, you can't describe verbally. It is the feeling. It is a wave inside you.

6. How does it feel for you when you are feeling empathic toward a patient?

The sensation is I really feel for the patient what sort of mental turbulence that patient is going through. I can feel their turbulence and in exchange I convey my consolation to that person. Yes, I do feel the turbulence, same time I feel that I am calming that patient too. Of course I do feel the turbulence. It's really not a good feeling, because naturally that patient is disturbed. You feel do feel inside you their pain and yes it is, you know, naturally we have to use our own defense mechanisms. We can't continue doing it. Yes, it does disturb me. You know I'm doing so many years of nursing (33) and I think I still get disturbed.

7. How is empathy a part of nursing?

Oh, yes, very much, empathy is a part of nursing. I think with the modern technology you can sort of cure the chemical problems of a patient. But with the empathy, you will try to treat the patient psychologically, and I'm sure, for example, like the mother holding the baby, there is a difference. You know they have done so much research too, you know when you do the breastfeed or the bottle feed, it is much 
difference. When you breastfeed you are giving all your efforts, all your affection to that baby, and it makes a difference. I think empathy is the same thing. It is a very, very good part of nursing. 
1. What do you think empathy is?

Well, I think empathy is your knack of understanding other people and not always verbally but emotionally how you communicate that.

2. Would you agree that empathy can be the ability to perceive the meanings and feelings of another person and to communicate that understanding to another?

Yes, I agree.

3. How might a nurse convey empathy to a patient?

I think nurse, especially anyone in a hospital, really the doctors come to see you. They really don't have much time for you. Though, doctors also should have empathy. But the nurse makes you sort of welcome to the hospital, they make you comfortable there. You need their empathy very much. They just sit by me. Just comforting me. To try to understand my feelings.

4. Have you ever felt a sense of energy being exchanged in a process of empathy?

$\mathrm{Oh}$, yes I did. Actually, especially when my son was in the hospital, the nurses around me, it was a oncology ward. The nurses supported me so much emotionally, mentally they really helped me to be strong, be supportive, to take it as a sport.

5. What do you think the nurse would do to let you know that she/he was feeling empathic toward you?

Their facial expression, their gesture, whether they are concentrating on me. Their mind is not away. You can tell if someone is having empathy on you.

6. What do you think the nurse would say if she/he was feeling empathic toward you?

Really they don't have to say much. They just have to be patient with you. Stand with you and be supportive of you. And if they come, and they can't spend much time with you, because they are so busy, they can't give you so much time, but even a couple of minutes, to come and even sit quietly with you. It's not a matter of words.

7. What do you think a nurse would feel if she/he was feeling empathic toward you?

I'm sure the nurse who is empathetic to you will feel your pain, will feel your comfort, or will feel whatever you are feeling because they are feeling that sort of thing all of the time, so they know exactly, might not know exactly how you are going through, they will at least know after seeing so many patients, how you are going through emotionally, feeling and they will be supportive to you.

8. How would it feel to you if the nurse was feeling empathic?

Oh, yes I would feel more comfortable in that environment. I wouldn't feel uneasy. I would be able to talk to her. I would be able to express myself. 
9. Is it important to you for a nurse to be empathic? Why?

Yes, definitely, because especially when you are in the hospital for such a long time. And if it's not empathetic environment, you won't be able to stay there, or you won't be able to cope with it. 
1. What do you think empathy is?

I believe that empathy is being able to feel and sense what maybe someone else is feeling or going through. To be sensitive to their emotions and feelings. Whatever they are going through at that time.

2. Would you agree that empathy can be the ability to perceive the meanings and feelings of another person and to communicate that understanding to the other?

Yes, I do believe it. I do agree with it, because you are able to perceive what they are going through and you are able to relate back to them that you understand what they are going through, or you are picking up from them. Whatever they are sensing.

\section{How does a person convey empathy?}

I think after you are able to pretty much perceive if that's the word you want, yes perceive or discern what that person is going through, it is just a matter of just a few moments that you are able to talk and understand what they are going through, immediately it is by giving them the time and I think you begin to lend an ear to them and making them feel very important and that they may be going through something very difficult, but you are not rushing them, you are making them feel very important in that situation. I guess it begins with lending a listening ear. That you listen to what they are going through.

4. Have you ever felt a sense of energy being exchanged in a process of empathy?

Yes, absolutely. I could think back many times Patty, when I have been talking to someone and they have been sharing their feelings or they have been sharing what they have been going through and because of my being there and just listening to their situation and just in the time spent with them, and just relating back and forth, when there is something maybe, and both individuals connect. Or maybe the other person that is going through the situation is realizing that you are really picking up what they are going through. And that there is a connection. Between both of you concerning that. It's not that you are just listening to them and just saying something real quick like "Yea, Yea, Yea," just to get it over and done with but you are really there. You are able to connect and feel the presence. Yes, exactly, there is a presence and you know directly that something is happening, it's like a confirmation that there is something. A connection, something that is happening between those two individuals at that moment. To me it is like a conformation that there is something above and beyond just communicating with someone. Something has taken place.

\section{How can you tell that you are conveying empathy?}

It could be in different ways. I could give you different examples. I'm talking to a person and I just feel like crying with them. I could relate and sometimes I even feel the pain, even in my gut. Then all of a sudden I just feel like I want to turn around and 
start weeping because of the pain that they are feeling or going through. I guess those are examples.

6. How does it feel for you when you are feeling empathic toward a patient?

For me, I feel very good concerning that because I feel that I am making a difference in that individual. That individual needs something at that time and I am being a vessel, bringing maybe a little bit of what that person needs. It makes me feel good because I feel that I am meeting one of their major needs at that time. When you are empathic with someone, you just might be meeting a very specific need that they have.

7. How is empathy a part of nursing?

Empathy is the essence of nursing. Because in nursing you can have clinical skills, you can have the theory, and you can have everything that nursing is all about, but if you don't have the empathy, you are lacking, it's not complete. It's not a whole. When you have empathy towards someone, I think it starts a process of healing towards that patient. Because through empathy you can provide hope, you can provide peace, you can provide. At least I think you can provide the certain essential needs of the individual to kind of find something that is going to help them. You can provide for them if you are able to pick up when they are going through and what they need. Then you can encourage them. You can provide hope, encouragement. And just relate with them to continue fighting in the process. It might not produce anything because they might just give up. But you must try. It's like the caring is a main essence of nursing. That caring is what nursing is all about. The core I would say. The root. And then everything else just stems from it. 
1. What do you think empathy is?

I think empathy is having understanding, feeling on the inside compassion, and being able to relate, identify with, or more so an understanding and compassion. Usually it is and I would say it is like having an affinity and you know, towards the individual.

2. Would you agree that empathy can be the ability to perceive the meanings and feelings of another person and to communicate that understanding to the other?

Definitely, that is my perspective on that. Usually it is displayed whether with physical contact or to share that, to demonstrate understanding or just listening to the person probably not even having to say anything. Indicating that it is understood and there is a common feeling of the issues involved.

\section{How does a person convey empathy?}

In my opinion, it is by listening. Just listening to the client is very good. Listening in an honest manner, I would say honest and evident manner that the client is being heard or listened to or basically trying to grant the request of the client. Maybe through the request of the individual that they have asked for. I would say just listening to them and if there is anything that is needed that would make that individual feel that they were worthwhile or valued, that their needs were being met.

4 Have you ever felt a sense of energy being exchanged in a process of empathy?

On occasion, I have and it is done basically by touching that individual or if an emotional state were apparent it could be through eye to eye contact. One that shows. For me I know sometimes I get very emotional. There may be a tear hear and there. I would try to be especially professional not let the tears happen but sometimes it can be a bit overwhelming and it becomes very evident that there is an exchange.

\section{How can you tell that you are conveying empathy?}

Truly there is something that shifts in me. There is a move. A emotional drive, or something that is a difference. There is an urge to listen more. There is an urge to reach out. There is a sense that I am needed. I need to be available to the individual. That is usually pretty distinct. That lets me know that this is happening. The process has at least started or has been established.

6. How does it feel for you when you are feeling empathic toward a patient?

I think in that time I, the need to probably prioritize the relationship at that time with the patient, whatever needs to be done for that patient, the caretaking, if I need to spend a longer time, if I need to do anything different, a sense of that I need to commit my time at that particular time to that individual to reach out and meet their needs. I need to become available. Emotionally as well as possibly if there are any physical needs. If I need to do anything tangible. 
7. How is empathy a part of nursing?

Empathy as part of nursing, I think really, should start. It should be an innate factor within the individual nurse. I think the profession would probably, should promote a deepening of that, and I think for the nursing profession, it should become. It should start with understanding. Communicating this understanding to the client. Whatever day to day activities are being done for the client it has to incorporate some component of empathy. That is to be sure it is not just routine work. That we do things for the individual because there is a reason and there is usually some kind of emotional attachment to each task. From talking about this, answering these questions, it is interesting. I am transposed back to past experiences. Each question I can relate to some kind of experience I have had and it really is not within the same scope. It is usually with different practices. There is always a reference for me. It is always with me. These questions have really evoked the reality of what has probably just been dormant waiting to be expressed. 


\section{What do you think empathy is?}

Empathy is caring or feeling compassion, similar to sympathy. The difference is in sympathy you feel sorry for someone and empathy you try to look in from their perspective. You try to put yourself into their place, into their shoes. Empathy is more so putting yourself in that persons situation and trying to understand how you would react in their situation. Putting yourself in their shoes.

2. Would you agree that empathy can be the ability to perceive the meanings and feelings of another person and to communicate that understanding to another? Yes.

\section{How might a nurse convey empathy to a patient?}

A nurse may show empathy to a patient by explaining to the patient that she understands that this is a painful procedure, maybe they haven't experienced it themselves, but they understand that the patient is going through some misery at the time. There is really nothing that either one of them can do but they try to help the person get through it.

4. Have you ever felt a sense of energy being exchanged in a process of empathy?

Yes. The two of you are communicating together during the empathy. There is a strong feeling of empathy. That you are somehow sharing a bond of energy while you are experiencing what they are going through at that time.

There is a event that comes to mind. The event when I had been in the hospital and had surgery for thyroid cancer. I had been under severe anesthesia afterwards. It was a five hour surgery. So therefore after the surgery I had been sleeping. I don't recall much of the afternoon. I don't recall any of the conversations with the doctor, post surgery. In the middle of the night, around midnight, the resident had come in to ask me how I was doing, and check my vitals, and how everything was going post surgery and he asked me how I felt. You know, being so young, and being diagnosed with cancer. I had no idea after the surgery, that it was cancerous tissue that was removed. I had my family around when I was sleeping. When he said that to me, I had no idea that I had cancer and he didn't know that I didn't know. Immediately, there were no words spoken but I felt empathy. Empathy for me from the resident for saying something like that, realizing that I didn't know anything about it. He felt empathy for me and I felt empathy for him in a way. I felt that he didn't know that I didn't know, and it wasn't for him to tell me. He was shocked that I didn't know and he didn't know what to say. He wasn't prepared for me not to know and having that reaction. I guess both of us were sharing a bit of empathy at that point for each other. He was shocked. It was almost as though he was ready to cry. He was embarrassed that this had happened. That he had put me on the spot like that. Put me in a situation where I 
wasn't ready to deal with it. At that point, he wasn't able to help me deal with it. $\mathrm{He}$ was completely shocked. He couldn't speak.

5. What do you think the nurse would do to let you know that she/he was feeling empathic toward you?

Possibly, maybe hold your hand, or try to look you in the eye and understand what you are going through and try to ask you, "Are you doing OK, is there anything I can do for you, tell me how you feel. Basically just communicate that they are with you in different ways.

6. What do you think the nurse would say if she/he was feeling empathic toward you?

I understand that this is uncomfortable for you. I wish that there was something I could do to prevent this or make this easier, the best way we can do is go through it.

7. What do you think a nurse would feel if she/he was feeling empathic toward you?

Probably share the same pain. Though it wouldn't be physical. Share quite a bit of the pain herself or himself. There is nothing that they can do. Kind of helpless in a way.I'm sure sometimes it is very frustrating, sometimes when a patient is in pain and there is nothing that the nurse can do to take care of the patient. Nothing that they can do to help them.

8. How would it feel to you if the nurse was feeling empathic?

I think it would take my mind off of what procedure was occurring. Make me feel alot better that someone understood that I was a person, and had feelings. Maybe wasn't reacting in a very positive way towards them, but it wasn't personal. Hopefully what ever pain I was going through would be easier to get through if I understood that someone else felt my pain. Literally felt my pain.

9. Is it important to you for a nurse to be empathic? Why?

Most definitely. I think it is a right of the patient to not go through situations in a cold environment, in a hospital setting without having the person who is doing the procedure staying with them. Understanding that this isn't their choice. The patient has to have the procedure, and it is uncomfortable for you, and that someone else realizes your pain. It makes it easier to get through. 
1. What do you think empathy is?

Well, this is my personal view of what I think empathy is. I think it is the ability to understand, at least be willing to understand where someone else may be. Whether it is psychological, or emotionally, or sometimes mentally. It is not necessarily agreeing with them but it may just be being able to comprehend their position. It is not like sympathy. It is more of a neutral emotion.

2. Would you agree that empathy can be the ability to perceive the meanings and feelings of another person and to communicate that understanding to another?

That was much more succinct. I like that one. I could definitely agree with that.

\section{How might a nurse convey empathy to a patient?}

Well, alot of times it is a nonverbal message. Not necessarily verbal. And alot of times even if a nurse is extremely busy and distracted through the sorts of things that happen on a daily basis but at that moment that they make eye contact. It may be when they enter the room or the moment when they call you by your name or ask how you are feeling and not just talk at you while they are staring at their papers but when there is a sense of recognition. It could just be in the gentle way that you feel when they may just put their hand on yours or a neutral part of your body. It could be in any number of ways.

4. Have you ever felt a sense of energy being exchanged in a process of empathy?

Almost all of the time. I think the way that, particularly when I am open myself. I think the way for energy is that it can happen anytime, anywhere, and it doesn't require special equipment. The way that I believe it happens is that to be able to stop the noise in one's mind and be present. And feel that person being present to you. Well, I think when communication happens, whether it is verbal or nonverbal, there is a definite energy that is a part of that.

5. What do you think the nurse would do to let you know that she/he was feeling empathic toward you?

Well, once again I don't necessarily think they would have to say anything. Empathy is communicated in nonverbal messages as well. It could be in an expression on the face. It could be body posture. What I would mean would be it would seem like there was a slowing down, and an ability to be available to somebody. That would be either in the expression of the voice, or your diction, it could be in the way the speed of your words. When you are saying, now what was your question again? Well, I think it could be very simple things. It could be just the way a bandage is removed. You know like just letting the person know that it might be painful, or you might experience a brief shock, the expression of just preparation. Slowing down again, to just say that although the nurse is not experiencing the same procedure, giving you the patient enough time to really know. Enough guidance to say, you know, you may experience something. I have 
had the experience you know where I have been given the equipment to figure out how I wanted to deal with it.

6. What do you think the nurse would say if she/he was feeling empathic toward you?

I already kinda answered that. It's not so much, they don't really need to say anything. It can be other actions. I think what I can add to what I said before is that people respond to love and people respond to it in alot of ways. I think a nurse especially being in a healing position, because sometimes people when they are in a hospital they are out of sorts themselves, they are away from their own environment, and sometimes it could just be the presence of how the nurse walks in the room, and once again, it does not have to be anything said in particular or anything done in particular. I think it is a state of mind. I guess it is almost like a spiritual self you see. To be willing to be available and open.

7. What do you think a nurse would feel if she/he was feeling empathic toward you?

Well, I think that there is a real strength in empathy. Because a nurse, coming from the training, and educationally, as well as alot of times the emotional experience of caring for people, especially after years of doing that, it can provide a medium available to people. By being available to people, I lost my trail right there. Oh, yes, I want to say that feeling empathy doesn't take anything away from anybody. It gives something, and so I think for a nurse to be empathetic it be considered a strength. Their healing nature and healing presence will permeate how they experience their patients and their patients illness.

8. How would it feel to you if the nurse was feeling empathic?

I think I will use the word empowered. I would feel, I would really be, well, I have been fortunate to have had that experience. The experience I had was the joy of not having my leg be the only member of my body that was being treated. That my whole person was being treated. That I was recognized as being more than just one unit of my body. And it was a very powerful experience. I felt really like I was encouraged. I was acknowledged. I was, I felt really healed. The opportunity was available to me with that condition.

9. Is it important to you for a nurse to be empathic? Why?

I was trying to imagine what it would be like not to have an empathic experience. Because that (empathy) is what I would seek out naturally. Not from the perspective that personally but from experience that I would put it on someone that they had to be empathetic. But I really think that it is a very powerful way to go about, you know, the world. I would just think that I would like that. 
1. The moment when you really connect.

\section{Significant Statements}

Nurses

2. They feel that you are really there for them.

3. It's being totally there, just strictly focusing on what they are saying.

4. It's not letting outside distractions take even a minute of your time away from them.

5. It's listening to what they are saying and letting them know that you are really hearing what they are trying to get across to you.

6. I felt that it left me with something. It definitely affected me.

7. It's feeling as though I am really connecting with somebody.

8. Once again it's just being present, just a feeling that I am here for you.

9. It might be just listening, just listening alone is a big part of it.

10. It's someplace you place yourself.

11. It's almost magical. Looking back a very magical moment.

12. You are taken to a different plane.

13. Empathy is every part of nursing, the biggest part of nursing, everything you do.

14. You place yourself in the place of the other person, to try to figure out how they are feeling.

15. You can see things from their perspective.

16. You can feel a certain bond with a person.

17. The bond can also energize you.

18. The bond feels like you are touching base with someone. It's more than just physical.

19. They are on the same wave length.

20. You can help them go towards these things in a way that is meaningful to that person.

21. It is a state of grace.

22. A moment in a connection with a person when the rest of the world stops.

23. You are only aware of what is happening at that moment, with the person you are with.

24. It is just between you and the person.

25. It is powerful. It must be the energy.

26. Finally, when I stop what else I am doing, then I may feel the energy as I feel more connected and attentive of the person and not the task.

27. I am not distracted.

28. Listening, even to the silence between us.

29. It wakes you up to remind you of that what you do is meaningful.

30. Empathy is an integral part of real nursing. There is meaning for both of you.

31. Meeting the person wherever they are.

32. You try to feel what they must be feeling. You try to get their perspective.

33. You listen first. 
34. You let them know what you know about what they are going through.

35. You touch them if that's what they need.

36. It's a special connection you can feel.

37. It's a back and forth feeling.

38. It's going beyond knowing the facts.

39. It's really knowing what the person is feeling. What all this means to the patient.

40. It is a special bond that you are aware of.

41. Something happens. You feel the connection of putting yourself in the person's place.

42. It's a strong bond.

43. The patient knows that you know too.

44. It's a rewarding feeling. It makes what you do worthwhile.

45. By holding the patient's hand you can convey. Just stand by the patient, hold their hand.

46. With a touch I can convey.

47. You can't describe it in words, it is the feeling, a wave inside you.

48. It's like breastfeeding, when you give all your efforts, all your affections to the baby.

49. You lend an ear, a listening ear to what they are going through.

50. My being there.

51. There is a presence and you know directly that something is happening.

52. Something above and beyond just communicating.

53. Trying to grant the request of the client.

54. Just listening, not even having to say anything.

55. Make that individual feel that they were worthwhile or valued.

56. It can be a bit overwhelming, it becomes evident that there is an exchange.

57. There is something that shifts in me. There is a move. An emotional drive.

58. There is an urge to listen more. An urge to reach out.

59. The need to prioritize the relationship at that time, whatever needs to be done for the patient.

60. A sense that I need to commit my time at that particular time to that individual.

61. I need to become available.

62. It's not just routine work.

63. We do things for the individual because there is a reason and there is some kind of emotional attachment.

64. It is always with me. 
Table 2

Significant Statements

Clients

1. I think it is when someone really cares about someone else.

2. They try to find out what how they are.

3. They care about how you feel.

4. They try to find out what you need.

5. She could remember you.

6. She could stay in your room for a while.

7. She could listen to you.

8. One nurse always came in to see me.

9. She didn't make me talk though.

10. She told me she knew I was real tired.

11. She could come to your room.

12. She would know if you just wanted to be quiet.

13. She wouldn't ask you alot of questions.

14. It would feel like someone cared.

15. You could rest so you get stronger.

16. Concern for one's being.

17. By listening well to the concerns.

18. It would be beneficial to my well-being.

19. By touch, you know by holding your hand.

20. Touch you, just hold your hand.

21. Just being there.

22. "I understand how you are feeling."

23. An understanding of what you are going through.

24. A helpful feeling.

25. I think it shows that they care.

26. To feel for you.

27. Put there arms around me.

28. Pay attention to you. Look at you when they are talking.

29. Try to understand you.

30. Just believe what you say and let you know that she believes in you.

31. "I care about you."

32. She remembered me.

33. It makes you feel important.

34. You almost feel like you are part of this floor's (pt. care unit) family.

35. You know that they care.

36. Like you belong.

37. I think empathy is your knack of understanding.

38. They just sit by me.

39. To try to understand my feelings. 
40. The nurses supported me so much emotionally, mentally.

41. Their facial expression, their gesture, whether they are concentrating on me.

42. Their mind is not away.

43. Stand with you and be supportive of you.

44. Even a couple of minutes.

45. To come and sit quietly with you.

46. It's not a matter of words.

47. Feel whatever you are feeling.

48. Feel more comfortable in that environment.

49. I would be able to express myself.

50. You put yourself into their place.

51. You are somehow sharing a bond of energy.

52. There are no words spoken, but I felt empathy.

53. They are with you in different ways.

54. I think it is the ability to understand, at least be willing to understand where someone else may be.

55. Alot of times it is a nonverbal message. Not necessarily verbal.

56. They may just put their hand on yours.

57. Particularly when I am open myself.

58. Stop the noise in one's mind and be present.

59. There is a definite energy that is part of that.

60. An ability to be available to somebody.

61. To be willing to be available and open.

62. Doesn't take anything away from anybody.

63. That my whole person was being treated. 
Table 3

Theme Clusters Aggregated from the Formulated Meanings.

Nurses

Empathy is associated with a sense of a connection between the persons involved.

1. The moment when you really connect.

7. It's feeling as though I am really connecting with somebody.

22. A moment in a connection with a person when the rest of the world stops.

26. Finally, when I stop what else I am doing, then I may feel the energy as I feel more connected and attentive of the person and not the task.

36. It's a special connection you can feel.

41. Something happens. You feel the connection of putting yourself in the person's place.

Empathy is associated with active listening.

5. It's listening to what they are saying and letting them know that you are really hearing what they are trying to get across to you.

9. It might be just listening, just listening alone is a big part of it.

28. Listening, even to the silence between us.

33. You listen first.

49. You lend an ear, a listening ear to what they are going through.

54. Just listening, not even having to say anything.

58. There is an urge to listen more. An urge to reach out.

Empathy requires a Focused Attention on the process occurring between the two individuals.

24. It is just between you and the person.

26. Finally, when I stop what else I am doing, then I may feel the energy as I feel more connected and attentive of the person and not the task.

27. I am not distracted.

39. It's really knowing what the person is feeling. What all this means to the patient.

48. It's like breastfeeding, when you give all your efforts, all your affections to the baby.

With empathy there is a response to meet the individual needs of the client.

53. Trying to grant the request of the client.

59. The need to prioritize the relationship at that time, whatever needs to be done for the patient.

60. A sense that I need to commit my time at that particular time to that individual.

61. I need to become available.

62. It's not just routine work.

63. We do things for the individual because there is a reason and there is some kind of emotional attachment.

Empathy is associated with a sense of presence.

2. They feel that you are really there for them.

8. Once again it's just being present, just a feeling that I am here for you. 
10. It's someplace you place yourself.

14. You place yourself in the place of the other person, to try to figure out how they are feeling.

50. My being there.

51. There is a presence and you know directly that something is happening.

Empathy is associated with an awareness of a change in energy.

6. I felt that it left me with something. It definitely affected me.

11. It's almost magical. Looking back a very magical moment.

12. You are taken to a different plane.

19. They are on the same wave length.

25. It is powerful. It must be the energy.

37. It's a back and forth feeling.

38. It's going beyond knowing the facts.

41. Something happens. You feel the connection of putting yourself in the person's place.

47. You can't describe it in words, it is the feeling, a wave inside you.

52. Something above and beyond just communicating.

56. It can be a bit overwhelming, it becomes evident that there is an exchange.

57. There is something that shifts in me. There is a move. An emotional drive.

64. It is always with me.

Empathy is associated with a description of the energy as a bond.

16. You can feel a certain bond with a person.

17. The bond can also energize you.

18. The bond feels like you are touching base with someone. It's more than just physical.

40. It is a special bond that you are aware of.

42. It's a strong bond.

Empathy is infused in nursing, it is an essential component.

13. Empathy is every part of nursing, the biggest part of nursing, everything you do.

29. It wakes you up to remind you of that what you do is meaningful.

30. Empathy is an integral part of real nursing. There is meaning for both of you.

Empathy is associated with self transposal and resonation with the experience of the client.

14. You place yourself in the place of the other person, to try to figure out how they are feeling.

15. You can see things from their perspective.

32. You try to feel what they must be feeling. You try to get their perspective.

41. Something happens. You feel the connection of putting yourself in the person's place.

43. The patient knows that you know too.

There is a spiritual dimension of empathy.

21. It is a state of grace.

Empathy is experienced with and understanding of the other. 
34. You let them know what you know about what they are going through.

43. The patient knows that you know too.

Touch is a way of expressing empathy.

35. You touch them if that's what they need.

45. By holding the patient's hand you can convey. Just stand by the patient, hold their hand.

46. With a touch I can convey.

Deliberative Nursing, a process of identifying the real needs of a client and deliberately selecting a intervention specific to their needs, is a part of the empathic process.

53. Trying to grant the request of the client.

59. The need to prioritize the relationship at that time, whatever needs to be done for the patient.

60. A sense that I need to commit my time at that particular time to that individual.

63. We do things for the individual because there is a reason and there is some kind of emotional attachment. 
Table 4

Theme Clusters Aggregated from the Formulated Meanings

Clients

Empathy is associated with the perception of a sense of being cared for by the nurse.

1. I think it is when someone really cares about someone else.

3. They care about how you feel.

14. It would feel like someone cared.

25. I think it shows that they care.

31. "I care about you."

35. You know that they care.

There is a sense of being remembered / that there is a lasting effect of your interaction.

5. She could remember you.

32. She remembered me.

Empathy is experienced when there is a sense of physical presence.

6. She could stay in your room for a while.

8. One nurse always came in to see me.

11. She could come to your room.

21 Just being there.

38. They just sit by me.

43. Stand with you and be supportive of you.

45. To come and sit quietly with you.

53. They are with you in different ways.

60. An ability to be available to somebody.

61. To be willing to be available and open.

Empathy is associated with active listening on the part of the nurse.

7. She could listen to you.

17. By listening well to the concerns.

Empathy is associated with a sense of enhance well-being.

15. You could rest so you get stronger.

18. It would be beneficial to my well-being.

Empathy includes an awareness of nonverbal communication.

9. She didn't make me talk though.

13. She wouldn't ask you alot of questions.

46. It's not a matter of words.

52. There are no words spoken, but I felt empathy.

55. Alot of times it is a nonverbal message. Not necessarily verbal.

Empathy is facilitated by touch.

19. By touch, you know by holding your hand.

20. Touch you, just hold your hand.

27. Put their arms around me.

56. They may just put their hand on yours.

Empathy is associated with a sense of feeling understood. 
22. "I understand how you are feeling."

23. An understanding of what you are going through.

29. Try to understand you.

37. I think empathy is your knack of understanding.

39. To try to understand my feelings.

54. I think it is the ability to understand, at least be willing to understand where someone else may be.

Empathy is associated with a sense of focused attention during which the nurse tries to assess specific individual needs.

2. They try to find out what how they are.

4. They try to find out what you need.

41. Their facial expression, their gesture, whether they are concentrating on me.

42. Their mind is not away.

Empathy includes a sense of energy being shared.

47. Feel whatever you are feeling.

51. You are somehow sharing a bond of energy.

59. There is a definite energy that is part of that.

62. Doesn't take anything away from anybody.

Transposal

50. You put yourself into their place.

Empathy is experienced with a sense of being treated holistically.

63. That my whole person was being treated. 


\section{Table 5}

The Exhaustive Description of Empathy - Nurse Perception

Empathy is associated with a sense of a connection between the persons involved. Empathy is associated with active listening.

Empathy requires a Focused Attention on the process occurring between the two individuals.

With empathy there is a response to meet the individual needs of the client.

Empathy is associated with a sense of presence.

Empathy is associated with an awareness of a change in energy.

Empathy is associated with a description of the energy as a bond.

Empathy is infused in nursing, it is an essential component.

Empathy is associated with self transposal and resonation with the experience of the client.

There is a spiritual dimension of empathy.

Empathy is experienced with and understanding of the other.

Touch is a way of expressing empathy.

Deliberative Nursing, a process of identifying the real needs of a client and deliberately selecting a intervention specific to their needs, is a part of the empathic process. 


\section{Table 6}

\section{The Exhaustive Description of Empathy - Client Perceptions}

Empathy is associated with the perception of a sense of being cared for by the nurse. There is a sense of being remembered / that there is a lasting effect of your interaction. Empathy is experienced when there is a sense of physical presence.

Empathy is associated with active listening on the part of the nurse.

Empathy is associated with a sense of enhance well-being.

Empathy includes an awareness of nonverbal communication.

Empathy is facilitated by touch.

Empathy is associated with a sense of feeling understood.

Empathy is associated with a sense of focused attention during which the nurse tries to assess specific individual needs.

Empathy includes a sense of energy being shared.

Transposal

Empathy is experienced with a sense of being treated holistically. 
Empathy as perceived by nurses is experienced as a connection with an individual when there is an awareness of a change in energy between the two. Concretization of this concept of energy is described as a bond. Empathy is a process that unfolds in an environment of active listening, authentic presence, focused attention and touch. Empathy involves an attempt to meet the individual needs of the client. The process of empathy is described as having a spiritual dimension to it accompanied by an understanding of the other and a sense of self-transposal and resonation with the experience of the other. The experience of empathy is felt to be an essential component of nursing. 


\section{Table 8}

\section{The Fundamental Structure of Empathy - Client Perception}

Empathy as perceived by hospitalized clients is experienced when there is a sense of presence of the nurses. The client associates empathy with feeling cared for by the nurse. Active listening, an awareness of nonverbal communication and the use of touch by the nurse contribute to the sense of sharing the process of empathy. Empathy is associated with a sense of being cared for individually in a climate that focuses attention on your own specific needs. It is sensed that the nurse transposes self in the process and in that process an energy is shared. This experience of empathy leads to a sense of enhanced well being. 